\title{
Dynamic Responses of Soils around a One-Hole Double-Track Tunnel with the Metro Train Meeting
}

\author{
Bo Pan $\left(\mathbb{D},{ }^{1}\right.$ Wei Zhang $\mathbb{D}^{1},{ }^{1}$ Jianqiu Cao, ${ }^{1}$ Xueyong Ma, ${ }^{1}$ and Mingliang Zhou ${ }^{2}$ \\ ${ }^{1}$ School of Earth Sciences and Engineering, Nanjing University, Nanjing 210023, China \\ ${ }^{2}$ College of Civil Engineering, Tongji University, Shanghai 200092, China \\ Correspondence should be addressed to Wei Zhang; wzhang@nju.edu.cn
}

Received 13 August 2019; Revised 1 November 2019; Accepted 14 December 2019; Published 13 January 2020

Academic Editor: Gabriele Cazzulani

Copyright $(0) 2020$ Bo Pan et al. This is an open access article distributed under the Creative Commons Attribution License, which permits unrestricted use, distribution, and reproduction in any medium, provided the original work is properly cited.

\begin{abstract}
The single-hole double-track shield tunnel with a large diameter has been one of the optimized schemes for those Metro meeting tunnels crossing long water areas. Compared with single-hole single-track tunnels, train-meeting scenarios occur in single-hole double-track tunnels, which results in a greater dynamic loading and a longer action time. By far, the thorough understanding of the dynamic response and liquefiability of the soils around the single-hole double-track tunnels, when crossing liquefiable soil layers, is still lacked. In this paper, a typical profile of Nanjing Metro Line 10, of the crossing-river section near Jiangxinzhou Station, is taken as an example. Based on the multibody dynamics, we established the train-rail coupling model to obtain the train dynamic load. Subsequently, in view of the single running scenario and four typical meeting scenarios, the train-tunnel-soil FEM model is developed to analyse the dynamical responses of the soils around the tunnel. The results indicate the vertical acceleration of the tunnel substrata exhibits an exponential attenuation trend with an increase of the distance; the horizontal acceleration of the ground surface exhibits an enlarged area within 10-25 m from the tunnel centerline. Also, the displacement of the soil layer under the tunnel increases cyclically in the period of the Metro train passing and rebounds slowly after the train passes. When the wheels of two Metro trains act simultaneously, the peak compression strain increases superimposedly; when the act is out of sync, the peak compression strain occurs concentrated and significant increase does not occur. Moreover, the larger the vibration amplitude the Metro train causes, the greater the excess pore water pressure occurs. Beyond a certain depth range, the influence of the vibration vanishes. The ratio of the maximal pore water pressure to the total stress is less than 1, suggesting that liquefaction does not occur in the silty-fine sand soil layer beneath the tunnel. The research results can be used to estimate the longitudinal differential settlement under long-term operation conditions and be helpful in regulating running speed of the Metro trains and planning the maintenance measures for the track flatness of the tunnel.
\end{abstract}

\section{Introduction}

Recent decades have seen a boom of the urban rail transit, which can effectively relieve the traffic congestion, in China [1]. Compared with the double-hole double-track tunnels, single-hole double-track tunnels, generally with greater diameters, can reduce the risks, costs, and periods of the construction [2].

Scholars have carried out a variety of studies on the propagation law of the vibration generated by the Metro train running through the tunnels in soil layers, mainly on the double-hole double-track tunnels [3-6]. Volberg [7] discovered that the surface wave is the dominant factor of the vibration caused by vehicle operation; also, vibration energy was found decreasing due to the diffusion of the elastic waves and the weakening in the elastic medium. Further discoveries include that the maximum vertical displacement of the base soil decreases linearly with the depth increase and the vibration level of the ground increases with the train speed and decreases with the distance away from the railway [8]. When propagating in the soils, the plastic waves are damped and weakened continuously by the soils $[9,10]$.

The random dynamic loads generated by the Metro operation induce dynamic responses in the soils around the tunnel [11]. Accelerating or braking a running train applies 
additional longitudinal forces on the rails, which induces the longitudinal and horizontal displacements and shear stresses in the soils under the railway tracks [12]. The train speed affects the load frequency and the train weight affects the load amplitude as train wagon dimensions affect both the frequency and load amplitude [13].

The rail-tunnel-foundation system is in a state of loading and unloading repeatedly as the Metro train passes through the tunnel, and the dynamic responses of different parts of the system vary simultaneously with the time and space. The long-term loading and unloading circularly may induce damages on the rail-tunnel-foundation system [14]. Note that the Metro train may pass through the liquefiable soil layers. As for the scenario that the liquefiable granular soil, for example, silty-fine sand, acts as the underlying soil layer of the Metro tunnel, the pore water pressure of the underlying soils, which is under the cyclic action of train's dynamic load, repeatedly accumulates and dissipates; the liquefaction might occur in the soils. Gong et al. [15] found that the pore pressure ratio of the soil is related to the loading frequency, dynamic stress, and other factors. When the dynamic stress ratio is greater than the critical value, the pore water pressure of the soil continuously increases and the effective stress gradually decreases, eventually leading to the liquefaction and soil failure.

Although single-hole double-track tunnels attain greater dynamic loads due to the Metro-train meeting, few studies are available on the dynamic responses and liquefaction potential of the soils around the single-hole double-track tunnel with the Metro-train meeting. In this paper, taking the section between Jiangxinzhou and Linjiang stations of Nanjing Metro Line 10 of China as a case study, we conducted a vehicle-track model by employing the multibody dynamics software Universal Mechanism (UM), obtaining the dynamic wheel-rail force of the A-type vehicle. Subsequently, the FEM model of the track-tunnel soil is developed. After validating the model by comparing with the measured results, the dynamic responses, of the soils around the tunnel and the liquefaction potential of the silty-fine sand layer beneath the tunnel, are analyzed. The results are helpful for understanding of the dynamic behaviours of the foundation soils of the single-hole double-track tunnels with the train meeting.

\section{Basic Principle}

Various irregularities exist on the surface of the rails [16]; wheels generate dynamic loads when moving on the irregular rails, as shown in Figure 1. With the relative displacement $\Delta z$ of the rail surface variation, the Hertz spring is stretched to produce the Hertz force, which is calculated according to the following equations:

$$
\begin{aligned}
& F_{r}=-k_{H} \Delta z, \\
& F_{w}=k_{H} \Delta z .
\end{aligned}
$$

The wheel-rail contact force is determined by Hertzian nonlinear elastic contact theory [17] as

$$
K_{H}=\sqrt[3]{\frac{6 E^{2} P \sqrt{R_{\omega} R_{r}}}{4\left(1-v^{2}\right)^{2}}},
$$

where $P$ is the static load; $R_{\omega}$ and $R_{r}$ are the cross-sectional radius of wheels and rails, respectively; $E$ is the elastic modulus of the wheel and rail, and $v$ is the Poisson ratio.

\section{Case Study}

3.1. Engineering Background. Metro Line 10 of Nanjing City of China crosses the Yangtze River at the interval of Jiangxinzhou and Linjiang Stations. The line connects Jiangbei New Town, Hexi District, and the main urban area. The soil layers, traversed by the Metro Line 10, mainly consist of the filling soil, clay, mucky clay, silty-fine sand, and gravelly sand [2]. The total length of the tunnel is $3.6 \mathrm{~km}$. It is the first single-hole double-track tunnel across the Yangtze River, with a design service life of 100 years. In this paper, a typical section, near Jiangxinzhou station, is used for a case study. The section is noted in Figure 2. Silty-fine sand, with a uniform grain size and partially intercalated, exists in the strata. Liquefaction might occur in the silty-fine sand layers under cyclic loading. Note that, in the long-term operation of the Metro, liquefaction, of the silty-fine sand foundation under long-term cyclic load, could cause longitudinal differential settlement, augmenting the evenness level of the track and eventually affecting the normal passage of the Metro trains [18].

3.2. Train-Meeting Scenarios. The train-meeting scenarios are firstly considered. Figure 3 illustrates a typical trainmeeting scenario at the research section. Note that the length of an A-type Metro train is $140 \mathrm{~m}$; the running speed $V$ is $60 \mathrm{~km} / \mathrm{h}$; the time required for the train completely passing through the section is $8.4 \mathrm{~s}$. It is assumed that when the left front of the train arrives at the position of the studied section, the length of the right front of the train departing from the section is $n L$, where $0<n<1, n$ denoting the proportion of the length of the front of the train departing from the section to the whole length of the vehicle. $T$ is the whole time of the train running over the research section.

The fronts of the left and right trains meet at the research section, with $T=8.4 \mathrm{~s}$, as shown in Figure 4(a). After the right train passes through the section in $4.2 \mathrm{~s}$, the left train heads to the section position exactly, with $T=12.6 \mathrm{~s}$, as shown in Figure 4(b). When the right train passes through the section completely, the left train heads to the section exactly, with $T=16.8 \mathrm{~s}$, as shown in Figure $4(\mathrm{c})$. The three scenarios shown in Figures 4(a)-4(c) are defined as Scenarios I, II, and III, respectively. Only the left Metro passes through the section, with $T=8.4 \mathrm{~s}$, as shown in Figure $4(\mathrm{~d})$, defined as Scenario IV.

3.3. FEM Model. The two-dimensional FEM model of the track-tunnel soil is developed using the PLAXIS. The horizontal distance and the height of the model are $100 \mathrm{~m}$ and $60 \mathrm{~m}$, respectively. The centre of the tunnel is located at $22 \mathrm{~m}$ underground. The inner diameter of the tunnel is $5.1 \mathrm{~m}$, and 


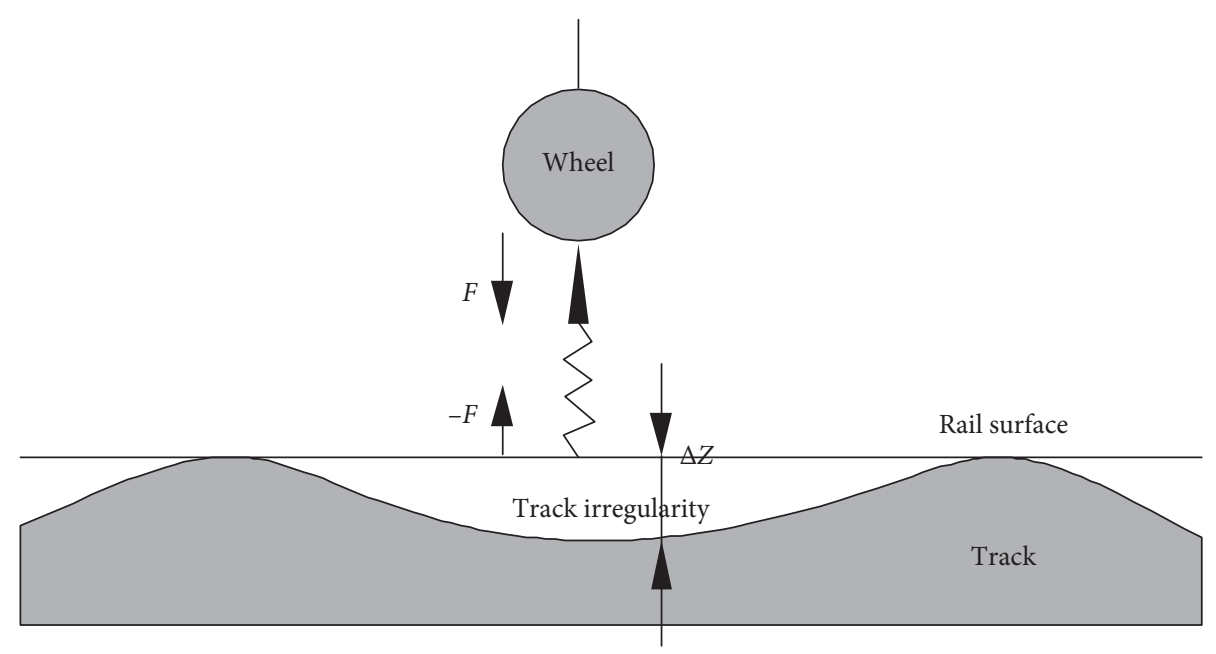

FIgURE 1: Wheel-rail contact illustration.

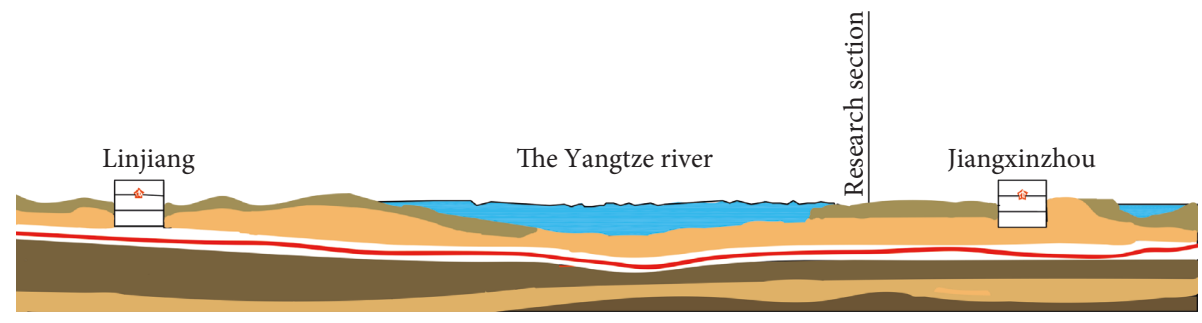

Figure 2: Research section of Nanjing Metro Line 10.

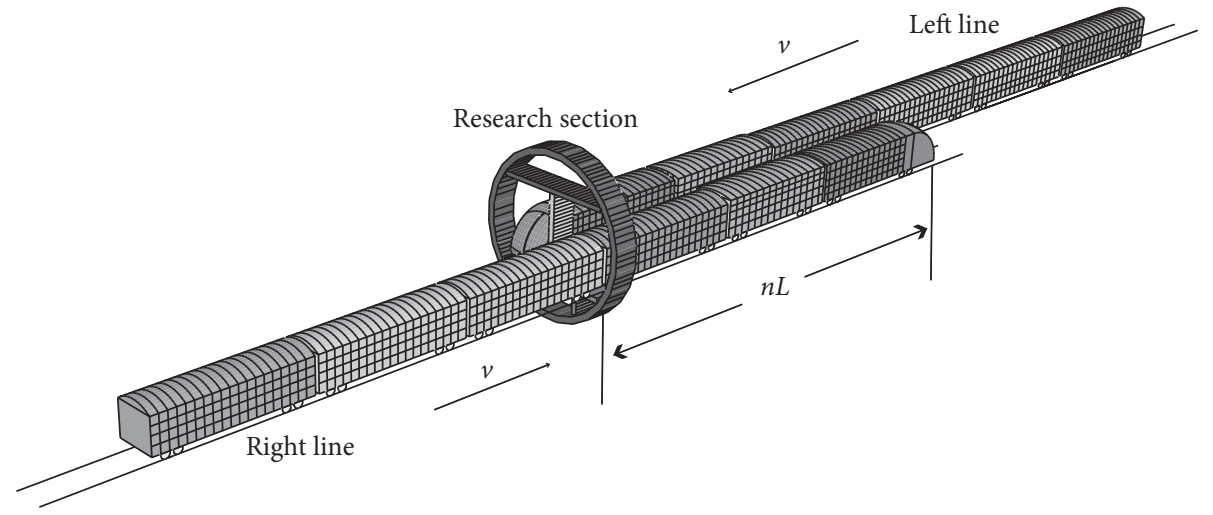

FIgURE 3: A typical scenario of train meeting in a single-hole double-track tunnel.

the thickness of the segment is $0.5 \mathrm{~m}$. The Mohr-Coulomb constitutive model is adopted; the damping ratios of soil and concrete are set as 0.03 and 0.05 , respectively. In order to eliminate the reflection of the scattered wave on the boundary, the viscous-absorbing boundary is applied at the bottom and left sides of the model, with free field boundary applied at the top of the model. The model consists of 2,829 units and 23,524 nodes, as shown in Figure 5. The soil layers and tunnel parameters are listed in Table 1.

3.4. Train Dynamic Load. In this paper, a numerical model of the wheel-rail loads is demonstrated by using the multibody dynamics software, Universal Mechanism, taking the A-type vehicles, commonly used in urban rail transit in China, as the Metro train type. The A-type vehicles have four motor $(M)$ cars and two trailers $(T)$, and the car sequence formation is coded as $+T-M-M-M-M-T+$. The train speed passing the section is assumed to be $60 \mathrm{~km} / \mathrm{h}$, which is the designed speed of the Metro train. Figure 6 depicts a simplified Metro train model. In view of the track structure, both rail and sleeper are simulated using the Euler beam model, with the bottom of the model set as rigid foundation, as shown in Figure 7. The parameters of the A-type trains are listed in Table 2.

In view of the established vehicle-rail coupling model, the wheel-rail force of the contact points can be obtained. 


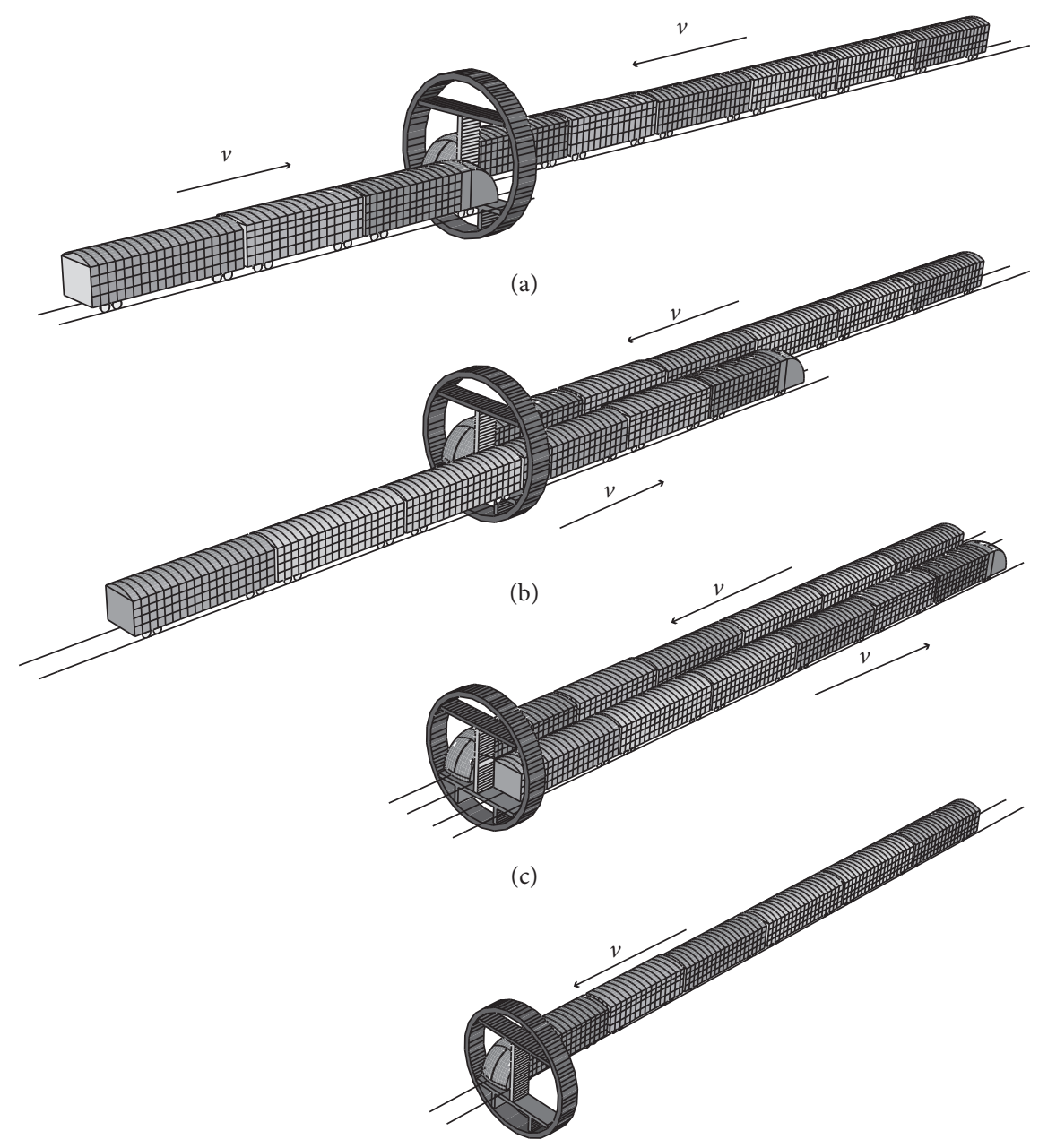

(d)
(a) Scenario I
(a) $n=0 \quad T=8.4 \mathrm{~s}$
(b) Scenario II
(b) $n=0 \quad T=12.6 \mathrm{~s}$
(c) Scenario III
(c) $n=0 \quad T=16.8 \mathrm{~s}$
(d) Scenario IV
(d) $n=0 \quad T=8.4 \mathrm{~s}$

FIgURE 4: Four typical train-meeting scenarios.

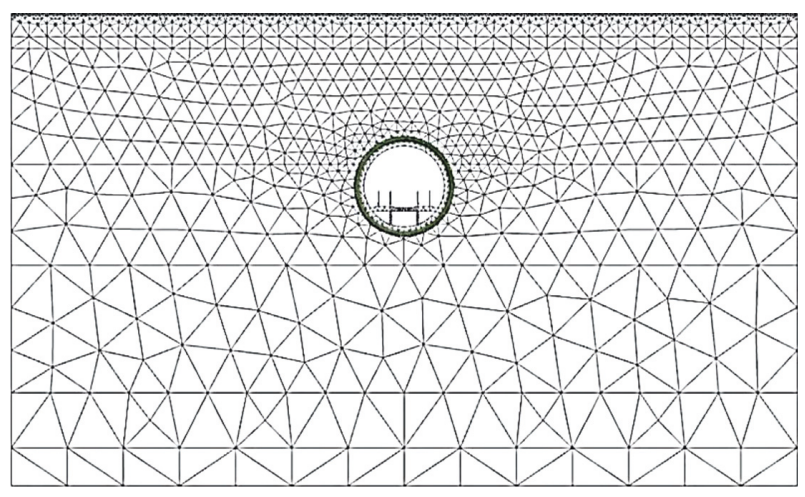

Figure 5: FEM model of the tunnel and soil.

For conciseness, the scope, of this paper, only focuses on the wheel-rail force of the first wheel pair of the personnel quota scenario trailer, as shown in Figure 8.
3.5. Model Verification. We selected the receiver point $B_{1}$ just above the research section on the ground and selected receiver points $A_{1}-A_{8}$ under the tunnel. Then, the receiver points are measured and simulated, respectively. Figure 9 exhibits the depth of the tunnel, the layout of the points, and the distribution of the soil layer, respectively, in $\mathrm{m}$ unit.

The numerical model is validated by field measurements. The monitoring system consists of the accelerometers, data acquisition system, gateway node, and notebook computer. Data acquisition was conducted using a JM3870 wireless dynamic/static vibration analysis system, with a sampling frequency of $256 \mathrm{~Hz}$. The AI050 piezoelectric accelerometer is used, with parameters shown in Table 3.

Figure 10 shows the measured and simulated acceleration curves of $B_{1}$ in the time domain. As can be seen, both curves have obvious 24 peaks, corresponding to the impact of 24 sets of wheel sets of the Metro train. The measured peak 
TABLe 1: Parameters of soil layers and the tunnel.

\begin{tabular}{|c|c|c|c|c|c|c|c|}
\hline Soil layers & $\begin{array}{c}\text { Layer } \\
\text { thickness }(\mathrm{m})\end{array}$ & $\begin{array}{c}\text { Deformation } \\
\text { modulus (MPa) }\end{array}$ & $\begin{array}{c}\text { Saturated unit } \\
\text { weight }\left(\mathrm{kN} / \mathrm{m}^{3}\right)\end{array}$ & $\begin{array}{c}\text { Friction } \\
\text { angle } \varphi\left({ }^{\circ}\right)\end{array}$ & $\begin{array}{c}\text { Cohesive force } \\
\qquad(\mathrm{kPa})\end{array}$ & $\begin{array}{l}\text { Void } \\
\text { ratio }\end{array}$ & $\begin{array}{l}\text { Poisson } \\
\text { ratio }\end{array}$ \\
\hline (1)-1 rock filling & 0.3 & 2.34 & 16.5 & 4.7 & 15 & 1.529 & 0.3 \\
\hline (2) -1 clay & 2.7 & 3.22 & 18 & 3.3 & 18 & 1.135 & 0.3 \\
\hline (2) -2 muddy clay & 1.5 & 3.5 & 18 & 4.6 & 11 & 1.106 & 0.3 \\
\hline (3)-1 silty-fine sand & 14.7 & 17.24 & 19.6 & 33 & 6 & 0.667 & 0.3 \\
\hline (3)-2 silty-fine sand & 12.8 & 16.12 & 19.6 & 31.8 & 6 & 0.674 & 0.3 \\
\hline (3)- 3 silty-fine sand & 16.2 & 17.1 & 19.6 & 32.6 & 6 & 0.693 & 0.3 \\
\hline (3) -4 gravelly sand & 7 & 25.3 & 20.8 & 38 & 2 & 0.58 & 0.3 \\
\hline $\begin{array}{l}\text { (4)- } 1 \text { moderately } \\
\text { weathered mudstone }\end{array}$ & 4.8 & 870 & 23.8 & 43.93 & 0.35 & - & 0.2 \\
\hline Tunnel segment & 0.5 & 30000 & 26 & 60 & 29.6 & - & 0.05 \\
\hline Box culvert & - & 28000 & 26 & 60 & 29.6 & - & 0.05 \\
\hline
\end{tabular}

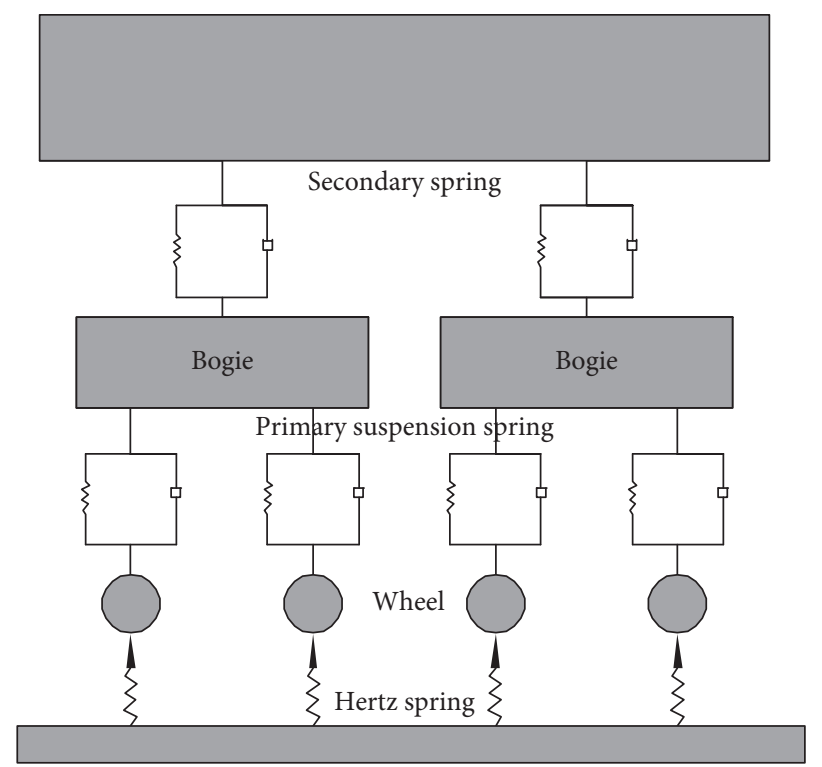

Figure 6: The simplified model of the Metro train [19].

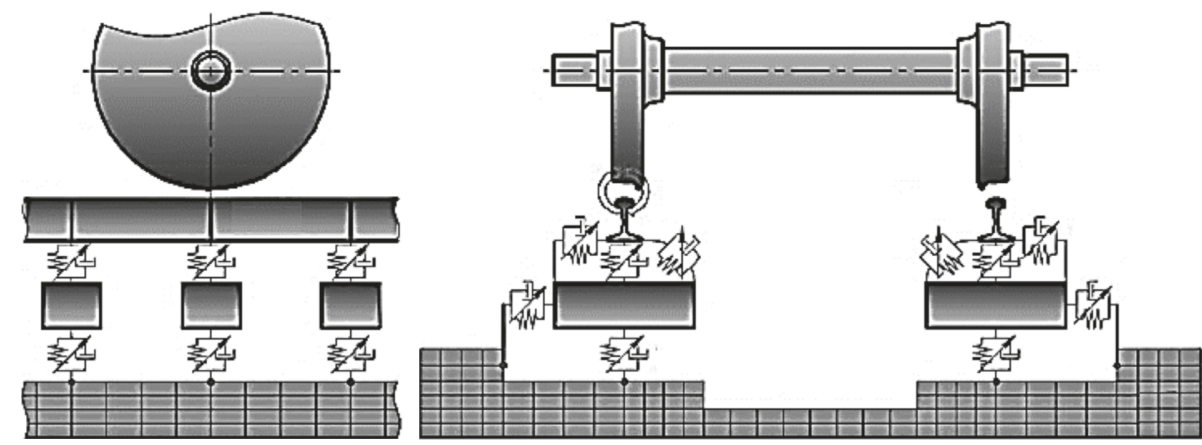

FiguRE 7: Track structure model [11].

value of the vertical acceleration of $B_{1}$ is between 0.06 and $0.1 \mathrm{~m} / \mathrm{s}^{2}$, and the simulated peak value is between 0.05 and $0.09 \mathrm{~m} / \mathrm{s}^{2}$, with an error less than $15 \%$. Background noises exist in the field test, making the profiles of the measured and simulation results vary.

Figure 11 shows the measured and simulated acceleration curves of $B_{1}$ in the frequency domain. Note that the measured acceleration frequency of $B_{1}$ mainly concentrates on 5 to $15 \mathrm{~Hz}$, while the simulated acceleration frequency concentrates on $0-20 \mathrm{~Hz}$, both in the low-frequency band. The maximum measured and simulated values of the peak acceleration are $0.1 \mathrm{~m} / \mathrm{s}^{2}$ and $0.083 \mathrm{~m} / \mathrm{s}^{2}$, respectively.

Basically, the measured and simulated results agree with each other. The numerical model can be assumed reasonable. 
TABLE 2: Train parameters.

\begin{tabular}{|c|c|c|}
\hline Parameters & Unit & Value \\
\hline $\begin{array}{l}\text { Vehicle length } \\
\text { (trailer/motor } \\
\text { power car) }\end{array}$ & $\mathrm{m}$ & $24.4 / 22.8$ \\
\hline $\begin{array}{l}\text { Body width } \\
\text { (floor area) }\end{array}$ & $\mathrm{m}$ & 3 \\
\hline $\begin{array}{l}\text { Body height } \\
\text { (when bowing } \\
\text { down) }\end{array}$ & $\mathrm{m}$ & $\leq 3.8$ \\
\hline Axle load & $\mathrm{t}$ & 16 \\
\hline Wheel set weight & $\mathrm{kg} \cdot \mathrm{m}^{2}$ & 2080 \\
\hline $\begin{array}{l}\text { Rotating inertia } \\
\text { of wheel-to- } \\
\text { wheel roll }\end{array}$ & $\mathrm{kg} \cdot \mathrm{m}^{2}$ & 749 \\
\hline $\begin{array}{l}\text { Rotating inertia } \\
\text { of wheel set } \\
\text { nodding head }\end{array}$ & $\mathrm{kg} \cdot \mathrm{m}^{2}$ & 81 \\
\hline $\begin{array}{l}\text { Rotating inertia } \\
\text { of wheel set } \\
\text { shaking head }\end{array}$ & $\mathrm{kg} \cdot \mathrm{m}^{2}$ & 1026 \\
\hline Frame weight & $\mathrm{kg}$ & 2310 \\
\hline $\begin{array}{l}\text { Rolling inertia of } \\
\text { frame }\end{array}$ & $\mathrm{kg} \cdot \mathrm{m}^{2}$ & 2080 \\
\hline $\begin{array}{l}\text { Rotating inertia } \\
\text { of nodding head } \\
\text { of frame }\end{array}$ & $\mathrm{kg} \cdot \mathrm{m}^{2}$ & 1405 \\
\hline $\begin{array}{l}\text { Rotating inertia } \\
\text { of shaking head } \\
\text { of frame }\end{array}$ & $\mathrm{kg} \cdot \mathrm{m}^{2}$ & 2450 \\
\hline $\begin{array}{l}\text { Rolling inertia of } \\
\text { car body }\end{array}$ & $\mathrm{t} \cdot \mathrm{m}^{2}$ & 159.3 \\
\hline $\begin{array}{l}\text { Rotating inertia } \\
\text { of body nodding }\end{array}$ & $\mathrm{t} \cdot \mathrm{m}^{2}$ & 2351.2 \\
\hline $\begin{array}{l}\text { Moment of } \\
\text { inertia of car } \\
\text { body shaking } \\
\text { head }\end{array}$ & $\mathrm{t} \cdot \mathrm{m}^{2}$ & 2033.9 \\
\hline $\begin{array}{l}\text { Longitudinal } \\
\text { stiffness of } \\
\text { primary } \\
\text { suspension (per } \\
\text { axle box) }\end{array}$ & $\mathrm{kN} / \mathrm{mm}$ & 17 \\
\hline $\begin{array}{l}\text { Transverse } \\
\text { stiffness of } \\
\text { primary } \\
\text { suspension (per } \\
\text { axle box) }\end{array}$ & $\mathrm{kN} / \mathrm{mm}$ & 1.6 \\
\hline $\begin{array}{l}\text { Vertical stiffness } \\
\text { of primary } \\
\text { suspension (per } \\
\text { axle box) }\end{array}$ & $\mathrm{kN} / \mathrm{mm}$ & 1.6 \\
\hline $\begin{array}{l}\text { Longitudinal } \\
\text { stiffness of } \\
\text { secondary } \\
\text { suspension }\end{array}$ & $\mathrm{N} / \mathrm{mm}$ & 165 \\
\hline $\begin{array}{l}\text { Lateral stiffness } \\
\text { of secondary } \\
\text { suspension }\end{array}$ & $\mathrm{N} / \mathrm{mm}$ & 165 \\
\hline $\begin{array}{l}\text { Vertical stiffness } \\
\text { of secondary } \\
\text { suspension }\end{array}$ & $\mathrm{N} / \mathrm{mm}$ & 373 \\
\hline
\end{tabular}

TABle 2: Continued.

\begin{tabular}{lcc}
\hline Parameters & Unit & Value \\
\hline $\begin{array}{l}\text { Wheel rolling } \\
\text { circle radius }\end{array}$ & $\mathrm{m}$ & 0.42 \\
$\begin{array}{l}\text { Wheelbase } \\
\begin{array}{l}\text { Bogie centre } \\
\text { distance }\end{array}\end{array}$ & $\mathrm{m}$ & 2.5 \\
\hline
\end{tabular}

\section{Analysis of Dynamic Soil Responses}

4.1. Acceleration Response. Figure 12 shows the acceleration curve of $A_{1}$ in the time domain when the train passes through the research section under various scenarios. In Scenario IV, the vertical peak acceleration and horizontal peak acceleration of $A_{1}$ are $0.82 \mathrm{~m} / \mathrm{s}^{2}$ and $0.51 \mathrm{~m} / \mathrm{s}^{2}$, respectively. Both accelerations vary slightly in quantity, indicating the responses of the soil are obvious within a certain distance from the tunnel floor. In Scenario I, because both trains move in the same time period when meeting, the synchronous superposition of the elastic waves occurs. The peak value of the vertical acceleration of $A_{1}$ is about twice that of the value of the Scenario IV, and the maximum value is $1.6 \mathrm{~m} / \mathrm{s}^{2}$. However, the horizontal acceleration value approaches 0 due to the elastic wave acting in the opposite direction. In Scenario II, when the two Metro trains meet in the research section, from $4 \mathrm{~s}$ to $8 \mathrm{~s}$, the dynamic load produces superposition effect. However, the peak acceleration does not increase significantly due to the asynchronism of the load cycles. The frequency of Scenario III exhibits the same trend as that of scenario IV, only with a doubled meeting time.

Figure 13 shows the peak acceleration curves of $A_{1}-A_{8}$. With an increase of the vertical depth, the peak acceleration decreases exponentially. In Scenario I, the peak value of the vertical acceleration is about double that of the other scenarios; the gap decreases significantly with the increase of the depth. At $23 \mathrm{~m}$ below the tunnel, the peak acceleration of the four scenarios is very close. With the increase of the propagation distance, the wave front extends; the damping effect of the soil and the vibration intensity of the wave gradually decrease. The variation trend of the horizontal acceleration in Scenario I is different from that in the other scenarios, and an amplification region appears at the depth from $5 \mathrm{~m}$ to $12 \mathrm{~m}$. The reason is that the velocity attenuation of the surface wave and body wave are not consistent on the surface, and the elastic wave is reflected and refracted repeatedly at the interface of the soil layers and the ground surface.

4.2. Displacement Response. Figure 14 depicts the displacement time-domain curve of $A_{1}$ under various scenarios. The train vibration induces the soil displacement; the larger the vibration intensity and duration, the greater the soil displacement. Thus, the displacements of Scenarios I, II, and III are larger than those of the scenario IV; the displacement increases during the period of the Metro train passing, and the soil rebounds slowly after the Metro train passing. Under 


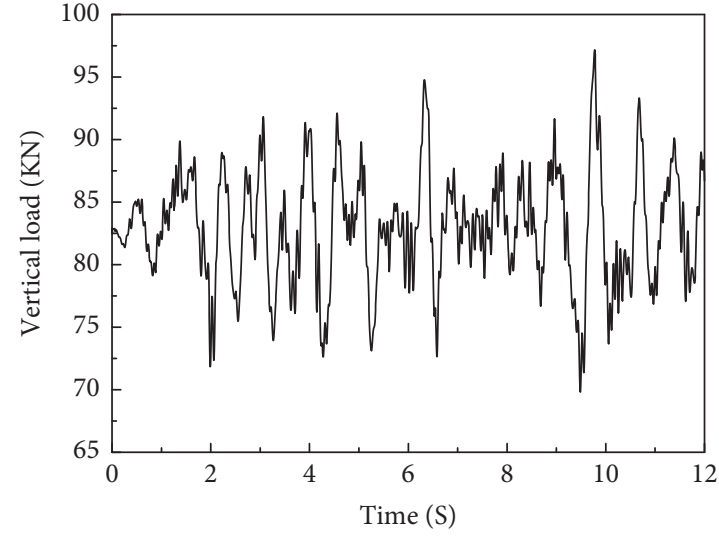

(a)

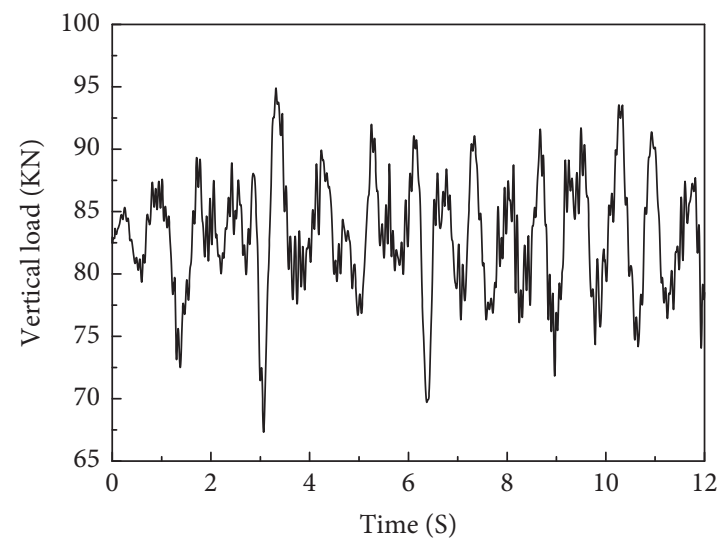

(c)

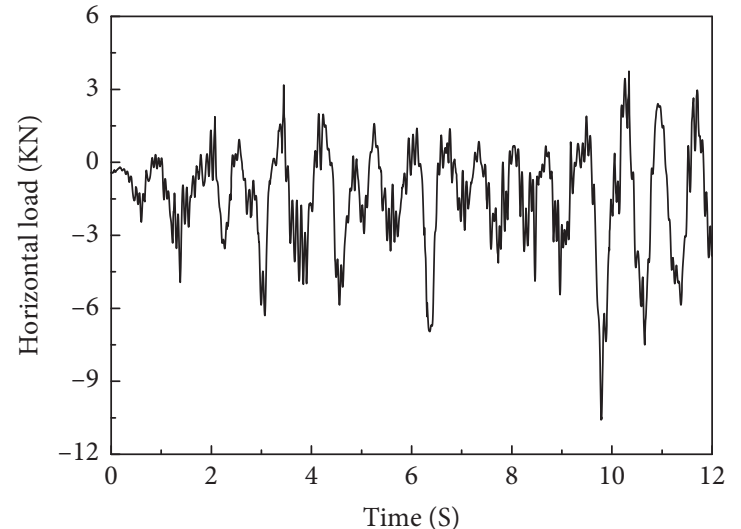

(b)

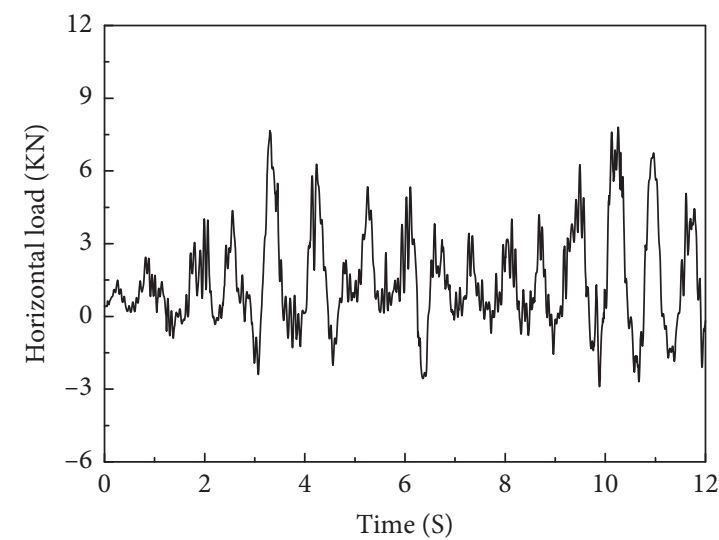

(d)

FIGURE 8: Wheel-rail force of the first wheel pair of the personnel quota scenario trailer. (a) Vertical force of the left rail. (b) Horizontal force of the left rail. (c) Vertical force of the right rail. (d) Horizontal force of the right rail.

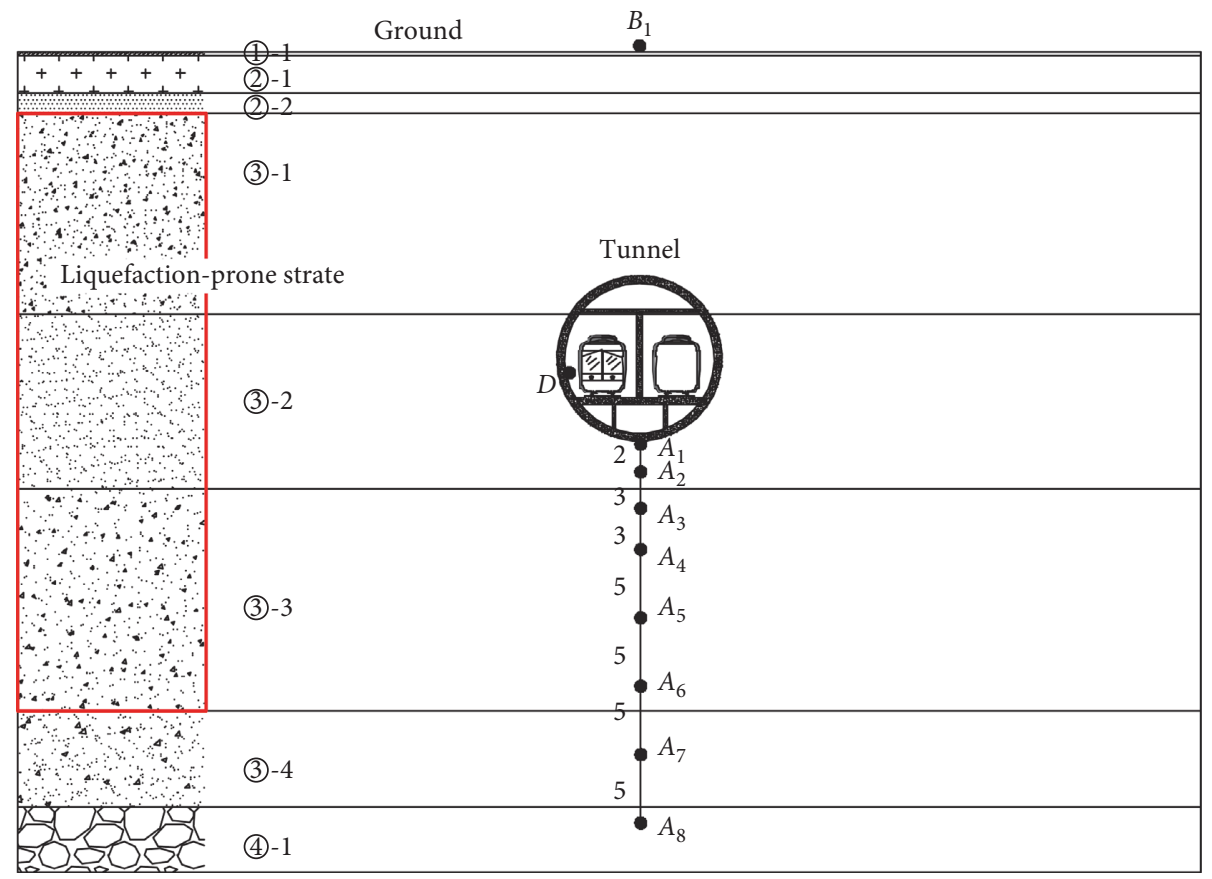

Figure 9: Profile of the soil types beneath the tunnel. 
TABle 3: Parameters of the piezoelectric accelerometer.

\begin{tabular}{lc}
\hline Parameters & Value \\
\hline Axial sensitivity $\left(20 \pm 5^{\circ} \mathrm{C}\right)$ & $\sim 50 \mathrm{mV} / \mathrm{ms}^{-2}$ \\
Measurement range (peak value) & $100 \mathrm{~ms}^{-2}$ \\
Maximum lateral sensitivity & $5 \%$ \\
Frequency response $(0.5 \mathrm{~dB})$ & $0.3 \sim 2500 \mathrm{~Hz}$ \\
Resonant frequency & $8000 \mathrm{~Hz}$ \\
Noise & $<0.08 \mathrm{~dB}$ \\
\hline
\end{tabular}

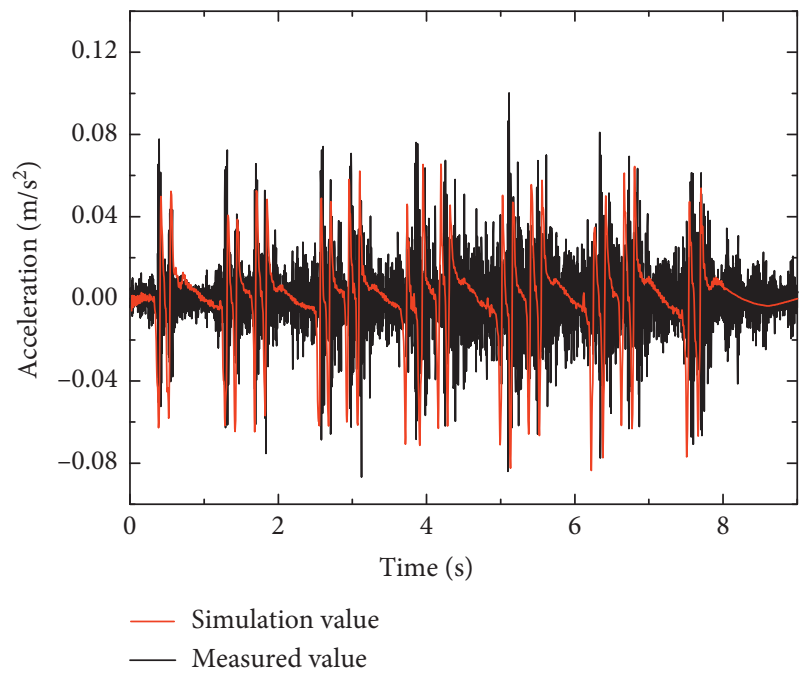

FIGURE 10: Comparison of measured and simulated acceleration in the time-domain curve.

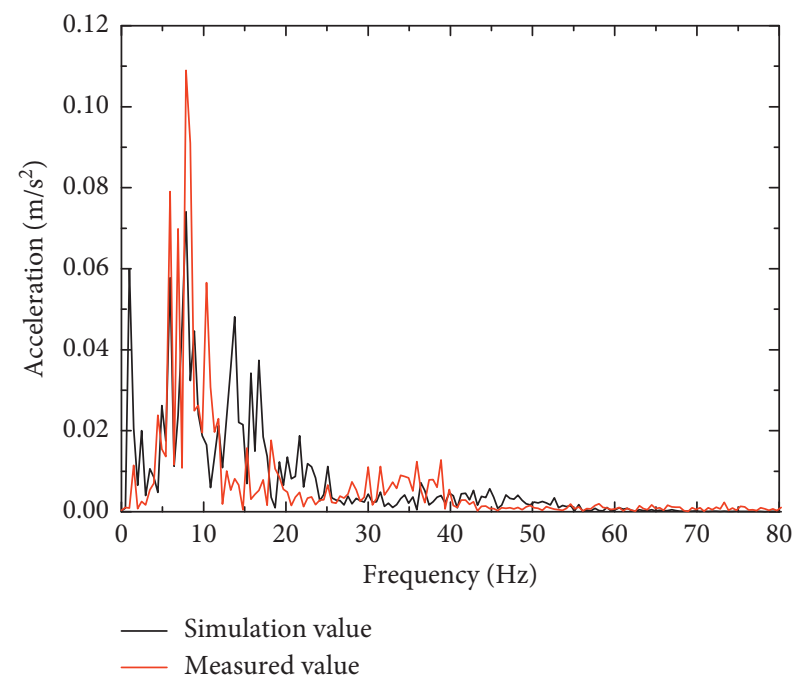

FIGURE 11: Comparison of measured and simulated acceleration in the frequency domain.

the sequential actions of the wheel sets of the Metro train, the vertical displacements of the scenarios I, III, and IV fluctuate monotonously to their maximum values and then rebound. Note that, in scenario II, the vertical displacement increases rapidly between $4 \mathrm{~s}$ and $8 \mathrm{~s}$ due to the overlapping effect of loads when the Metro train meets; the vertical displacement fluctuates repeatedly in the range of $3.5 \mathrm{~mm}-5 \mathrm{~mm}$ between
$7 \mathrm{~s}$ and $12 \mathrm{~s}$ instead of monotonously increasing and rebounds after the fluctuation.

Figure 15 exhibits the vertical displacement of the soil around the tunnel after the Metro train passes through the section under various scenarios. At the same elevation, the soil displacement around the tunnel decreases with the increase of the distance from the vibration source; the soil displacement decreases with the increase of the depth. When Metro train passes through the tunnel, the contour plot of the vertical displacement attenuates elliptically to the surrounding area. In scenario I, due to the same dynamic load period, when the two Metro trains passing through the research section at the same time, the contour plot of the vertical displacement exhibits axisymmetry with the tunnel centerline; the maximum vertical displacement of the tunnel reaches $5.24 \mathrm{~mm}$. In scenario IV, only the left Metro train passes through the research section, exerting eccentric load; the displacement on the left side of the tunnel is obviously larger than that of the other side. In Scenarios II and III, the left Metro departs from the section later than the right Metro train; the vertical displacement on the left side of the tunnel is slightly larger than that of the other side; the maximum displacement of the two scenarios is very close, $4.72 \mathrm{~mm}$ and $4.62 \mathrm{~mm}$, respectively.

4.3. Dynamic Strain Response. Figure 16 exhibits the strain time-domain curve of $A_{1}$ under four scenarios. Obviously, under the action of the wheel sets, the peak compressive strain occurs beneath the tunnel. When wheel sets are not active, the compressive strain decreases rapidly to 0 . In Scenario IV, only one Metro train is in operation; the maximum compressive strain of $A_{1}$ is $172 \mu \varepsilon$. When the wheel sets of two Metro trains act simultaneously, the peak compression strain increases superimposedly; in Scenario I, the maximum compressive strain is $342 \mu \varepsilon$, approximately twice the value of Scenario IV. When the wheel sets of two Metro trains are not synchronized, the peak compressive strain appears intensively and does not increase significantly; in Scenario II, the maximum compressive strain is $226 \mu \varepsilon$, about 1.32 times the value of Scenario IV. The maximum compressive strain of Scenario III is the same as that of Sscenario IV, but the lasting time is doubled.

Figure 17 exhibits the maximum dynamic strain curves of $A_{1}-A_{8}$. With an increase of the vertical depth, the maximum dynamic strain decreases linearly. Because of the damping effect of soil materials, the dynamic strain attenuates continuously. The maximum dynamic strain decreases rapidly with the increase of the depth within $5 \mathrm{~m}$; the maximum dynamic strain decreases linearly in the range of $5 \mathrm{~m}$ to $25 \mathrm{~m}$ and finally decreases to about $3 \mu \varepsilon$ under all the four scenarios. At the same depth, due to the different intensities and duration of the vibration, the trend of the dynamic strain under different scenarios yields Scenario I $>$ Scenario II $>$ Scenario III $>$ Scenario IV; the dynamic strain in Scenario III is close to that of Scenario IV.

4.4. Excess Pore Water Pressure. Figure 18 exhibits the timedomain curve of the excess pore pressure of $A_{1}$ under four 


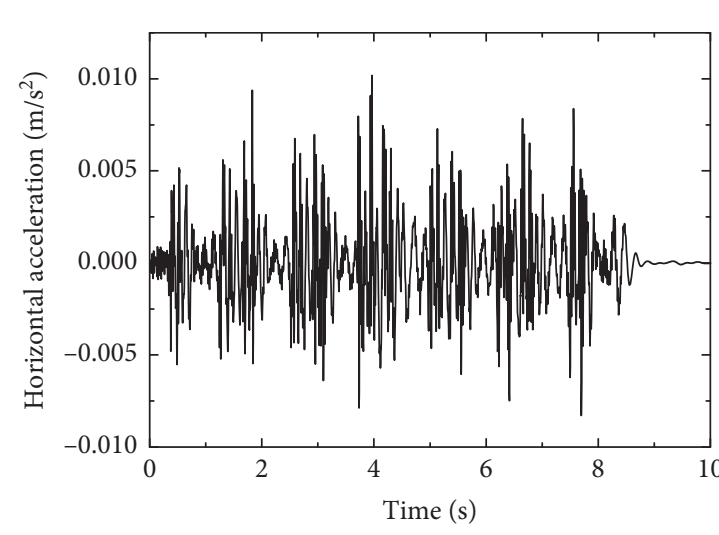

_- Scenario I

(a)

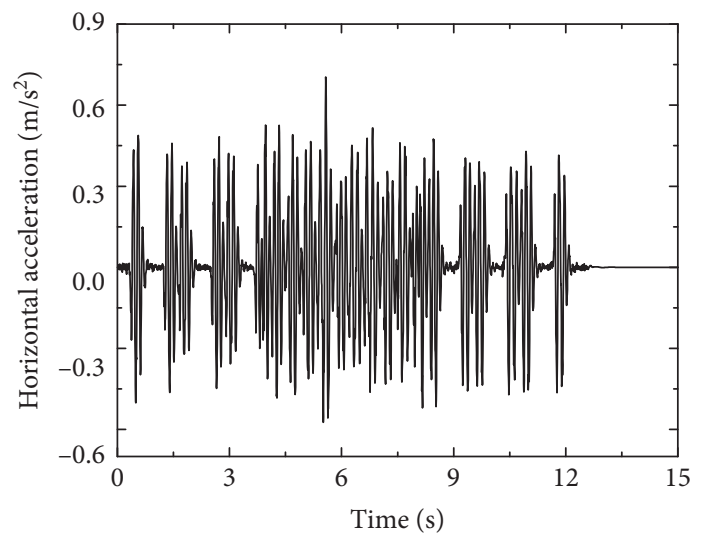

_ Scenario II

(c)

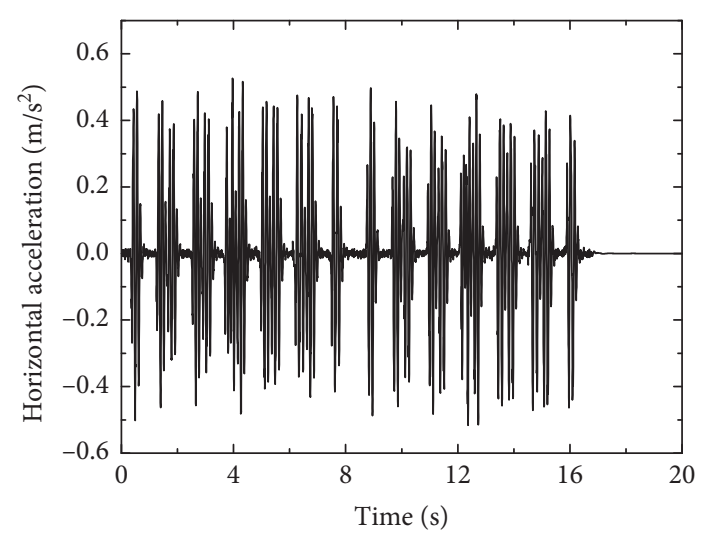

- Scenario III

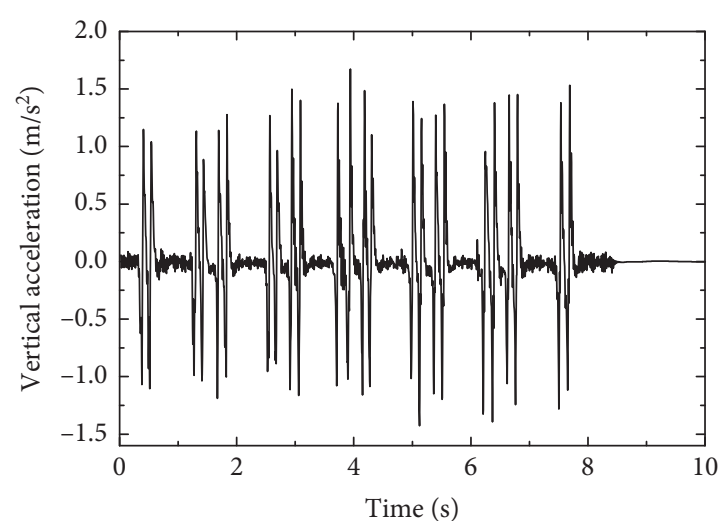

— Scenario I

(b)

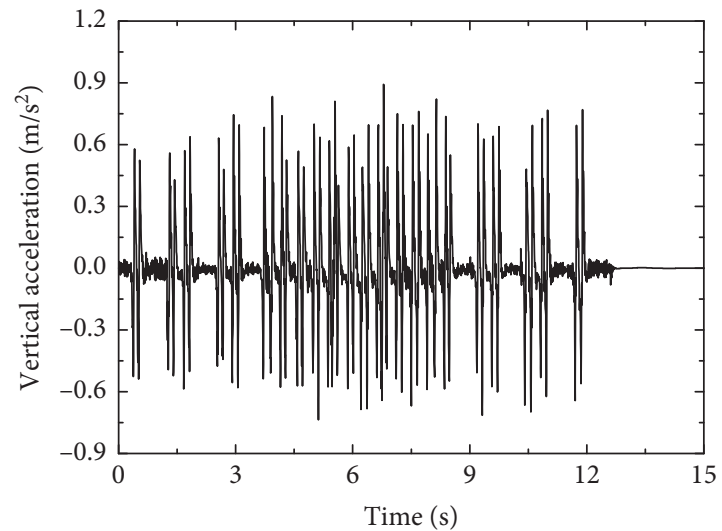

_- Scenario II

(d)

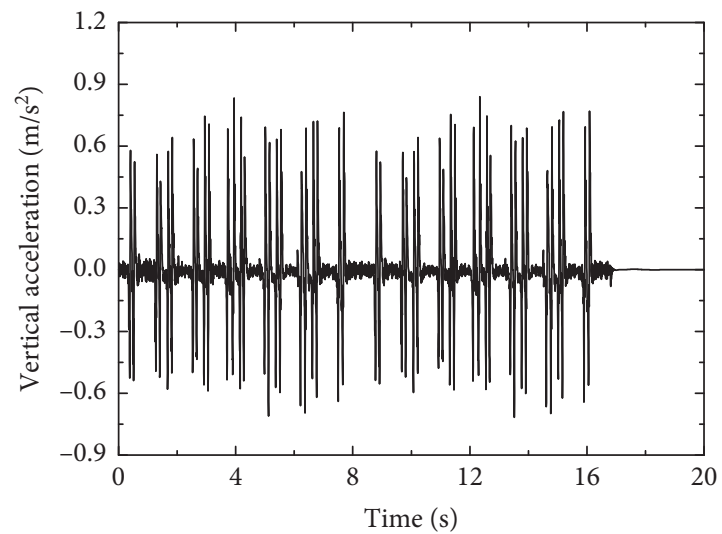

_ Scenario III

(e)

(f)

FIGURE 12: Continued. 


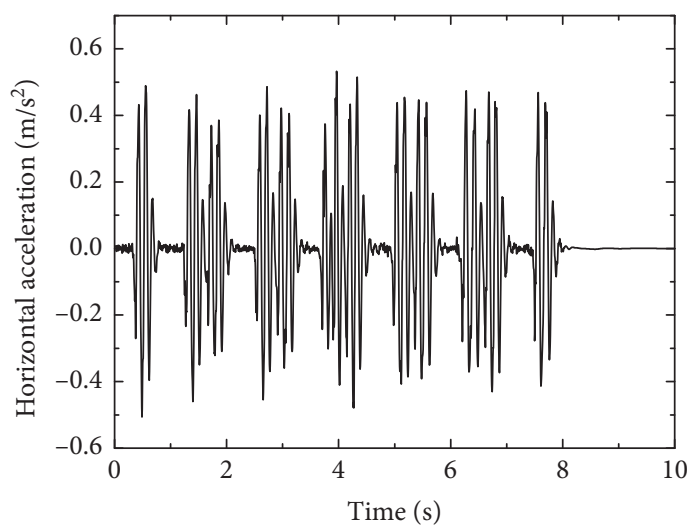

- Scenario IV

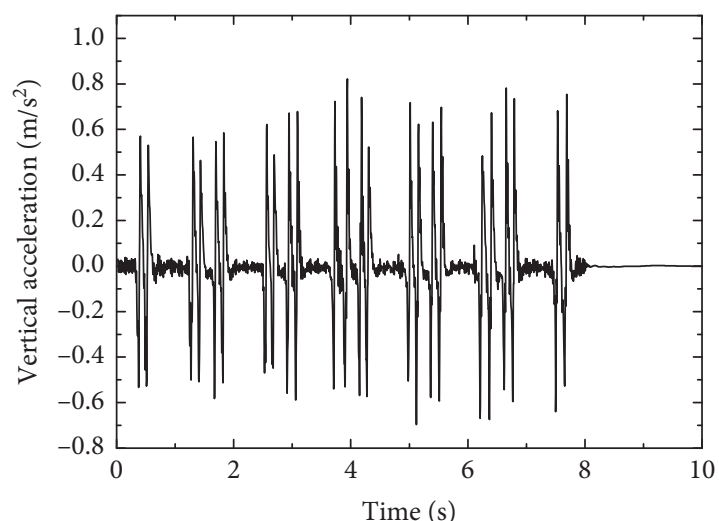

Scenario IV

(h)

Figure 12: The acceleration curve of $A_{1}$ in time domain. (a, c, e, g) Horizontal. (b, d, f, h) Vertical.

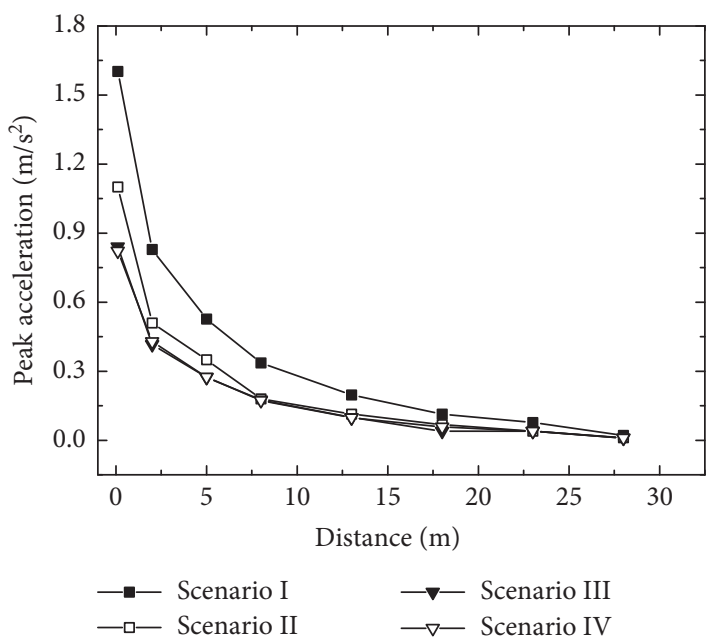

(a)

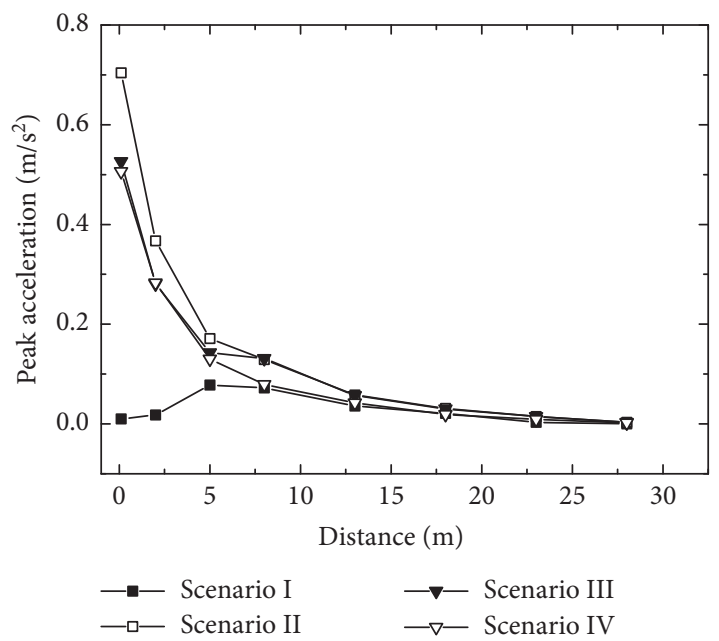

(b)

Figure 13: Trend of the acceleration variation. (a) Vertical acceleration. (b) Horizontal acceleration.

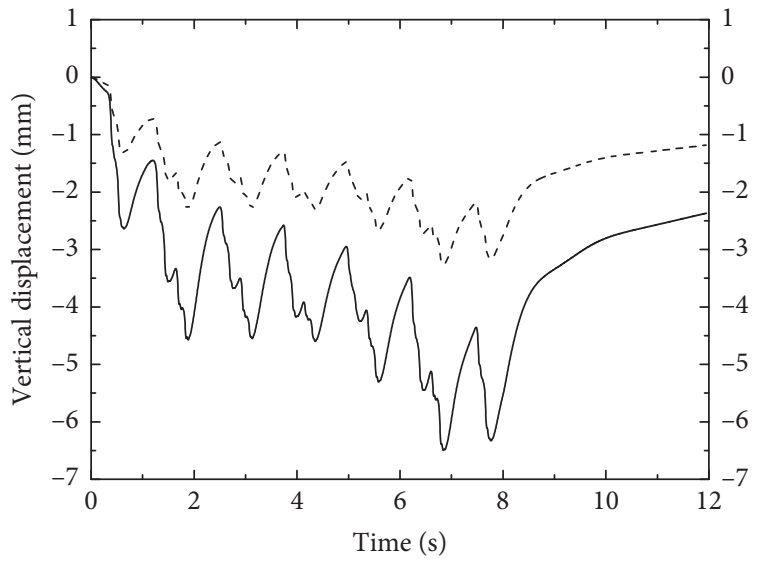

- Scenario I

- . - Scenario II

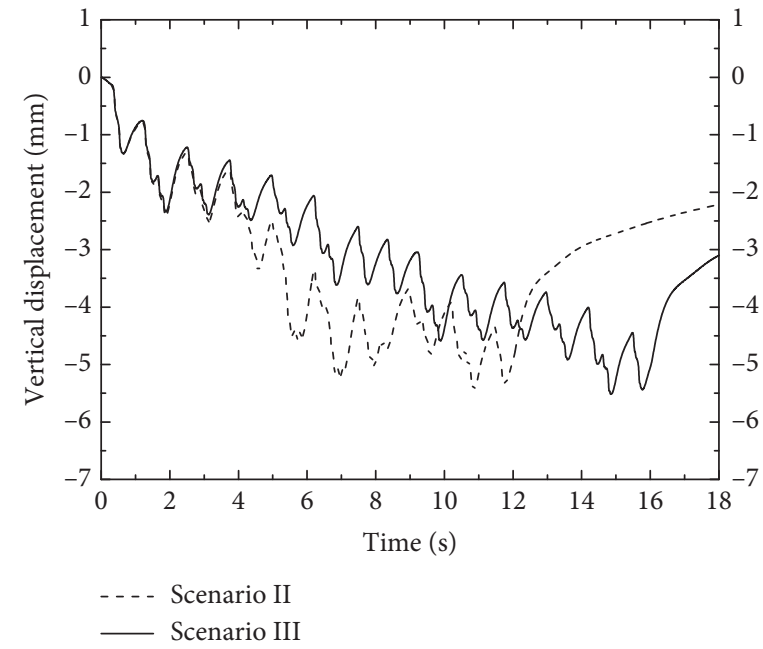

(b)

(a)

Figure 14: The displacement time-domain curve of $A_{1}$. 


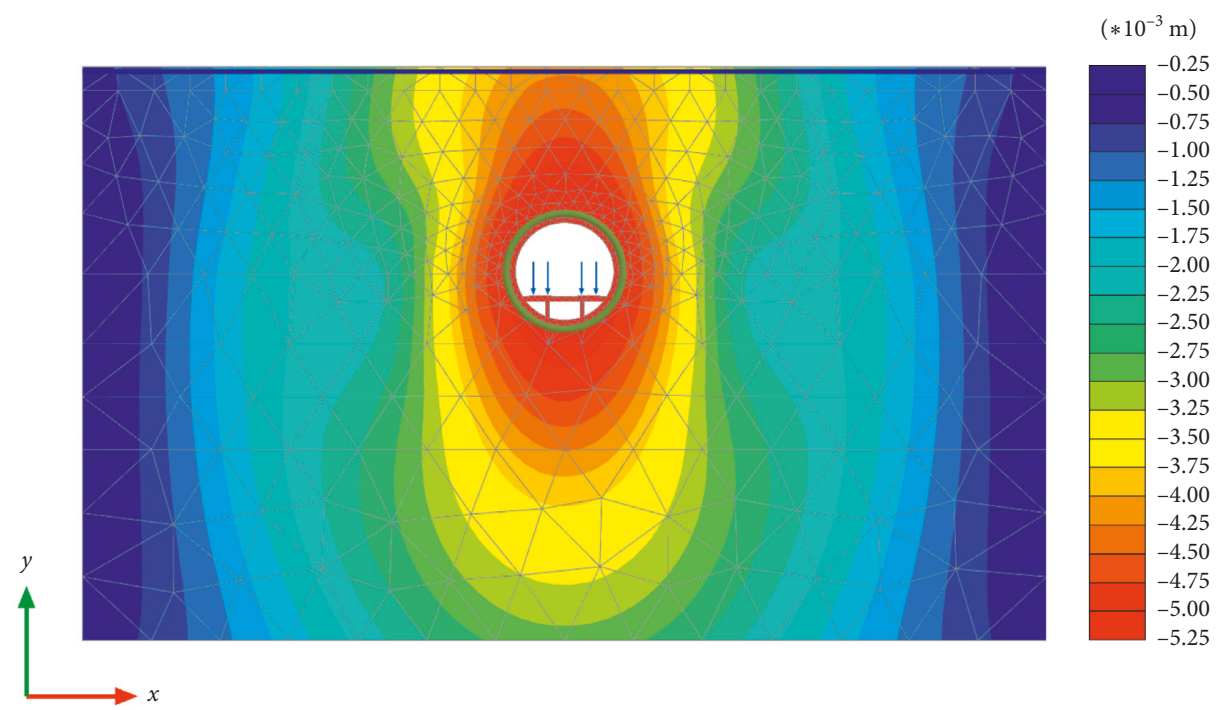

(a)

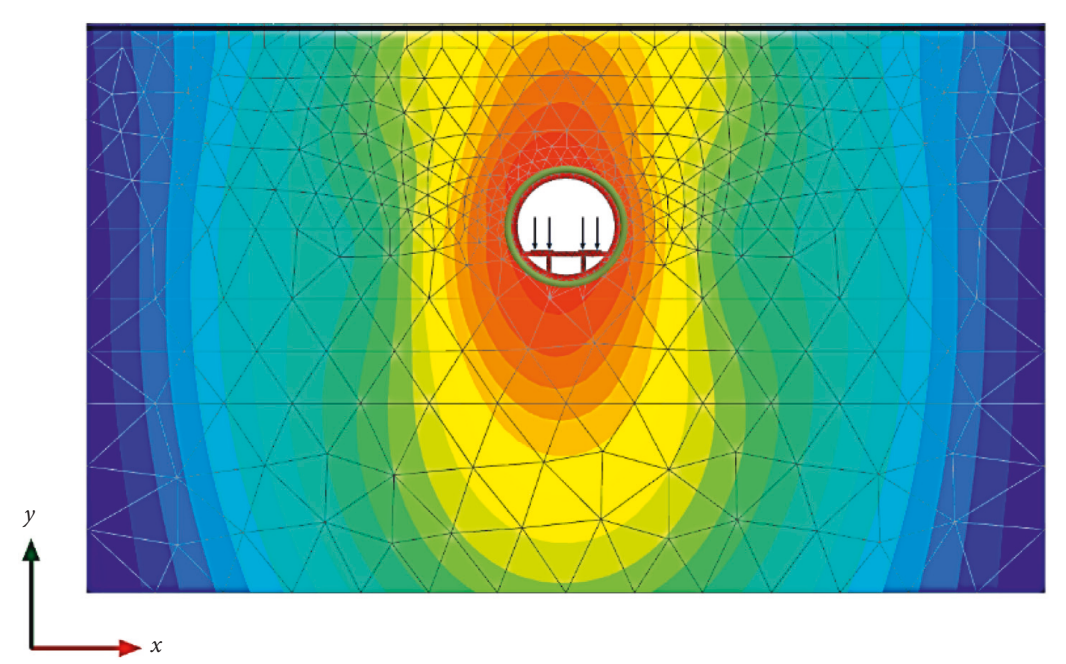

$\left(* 10^{-3} \mathrm{~m}\right)$

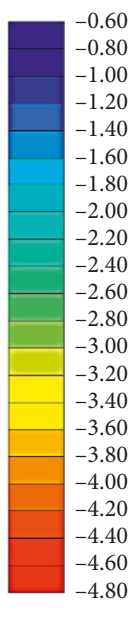

(b)

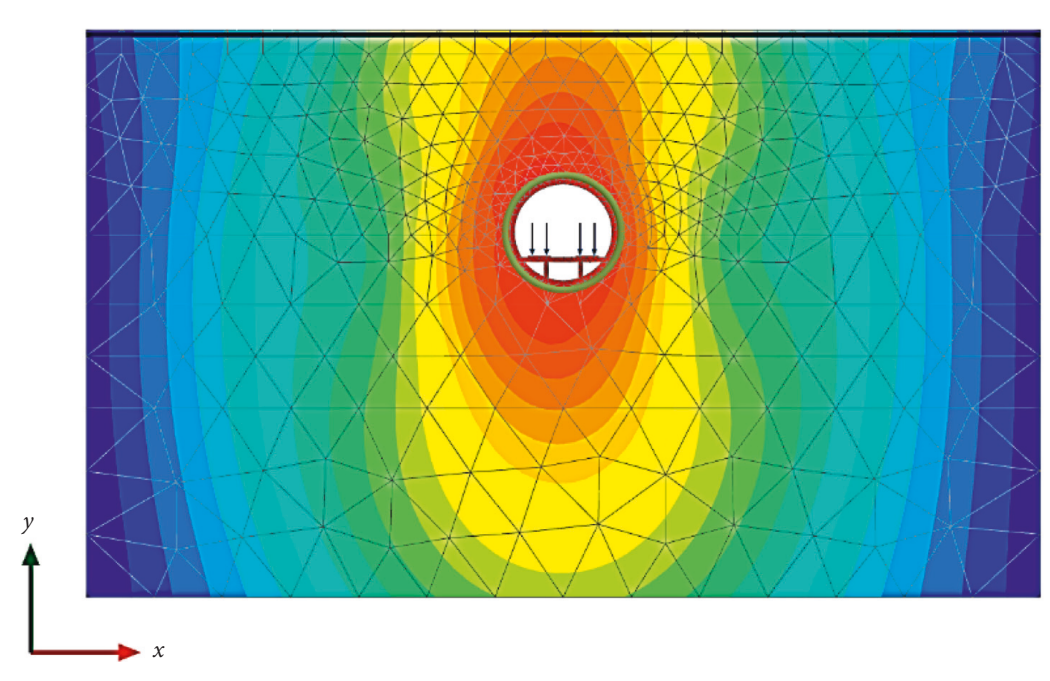

$\left(* 10^{-3} \mathrm{~m}\right)$

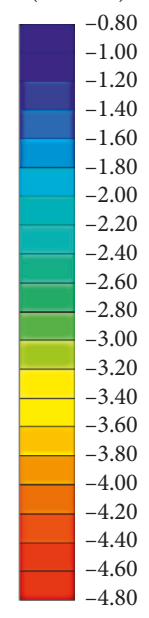

(c)

Figure 15: Continued. 


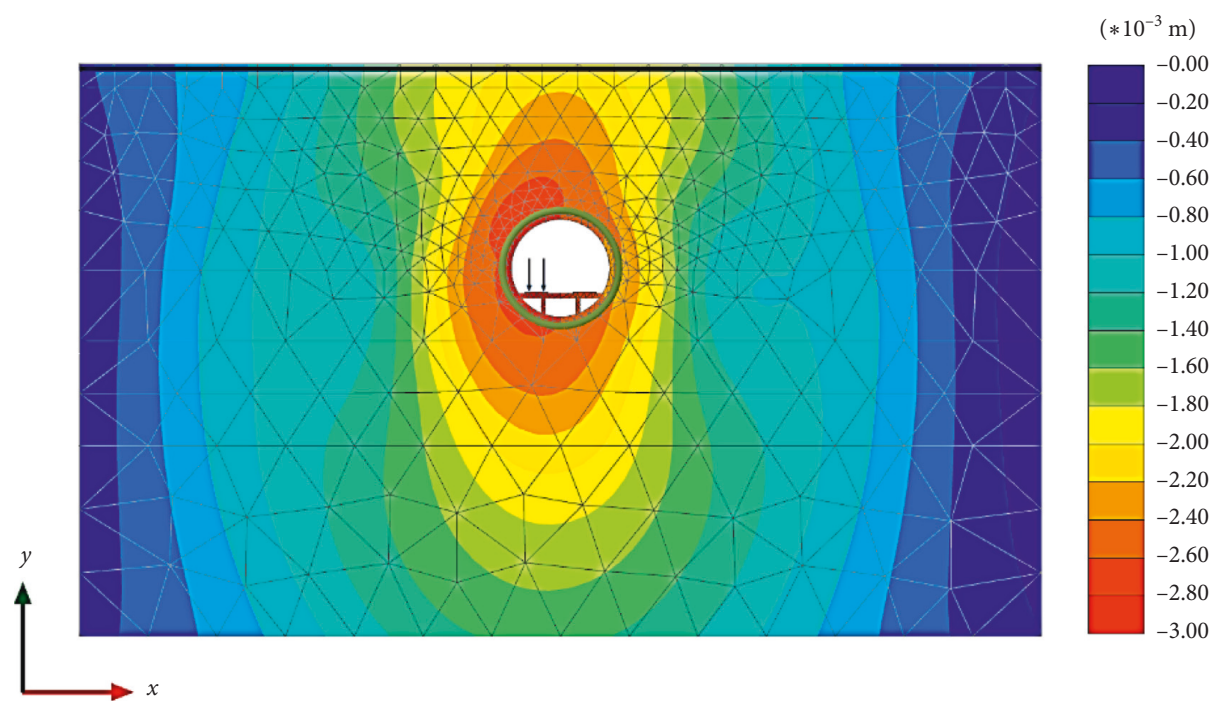

(d)

FIgURE 15: Vertical displacement contour plots of the four scenarios. (a) Scenario I. (b) Scenario II. (c) Scenario III. (d) Scenario IV.

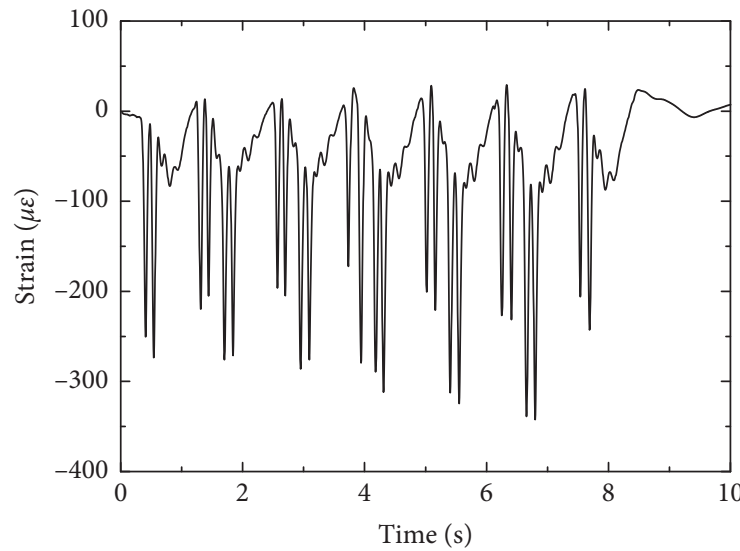

- Scenario I

(a)

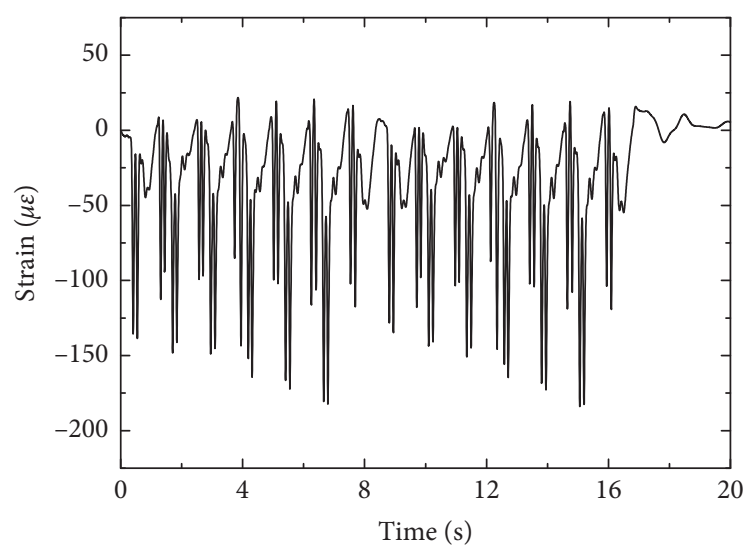

Scenario III

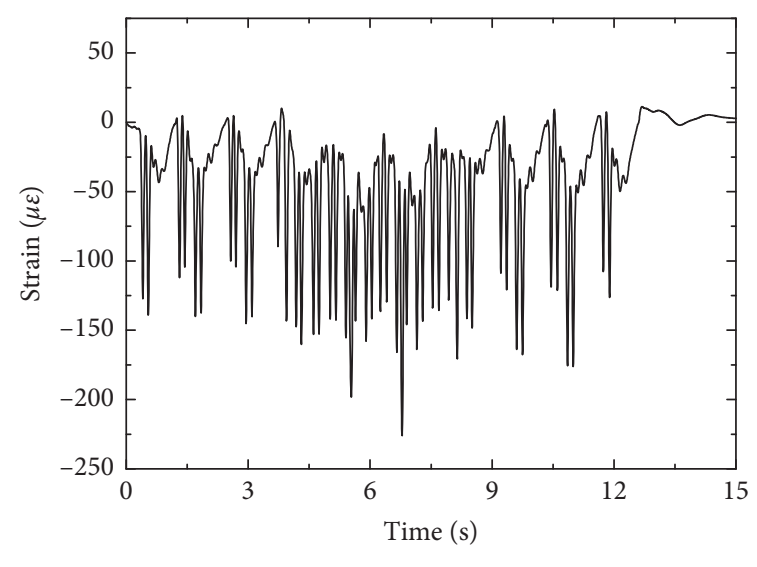

(b)

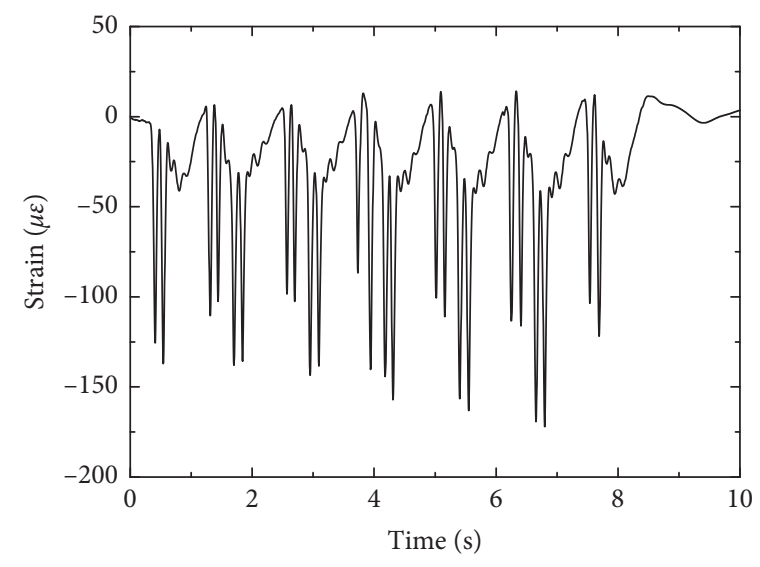

(d)

FIgure 16: The strain curve of $A_{1}$ in time domain. (a) Scenario I. (b) Scenario II. (c) Scenario III. (d) Scenario IV. 

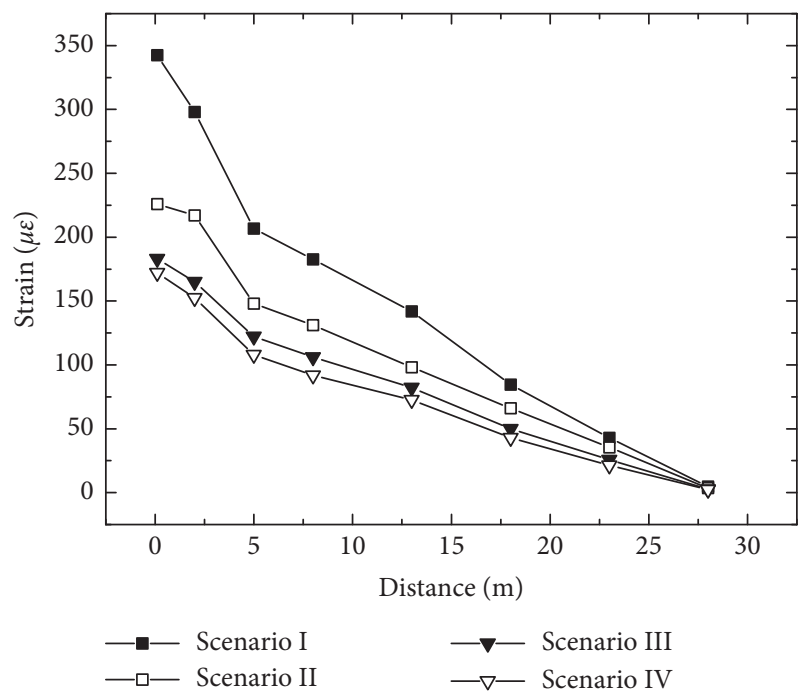

Figure 17: Trend of the maximum dynamic strain variation.

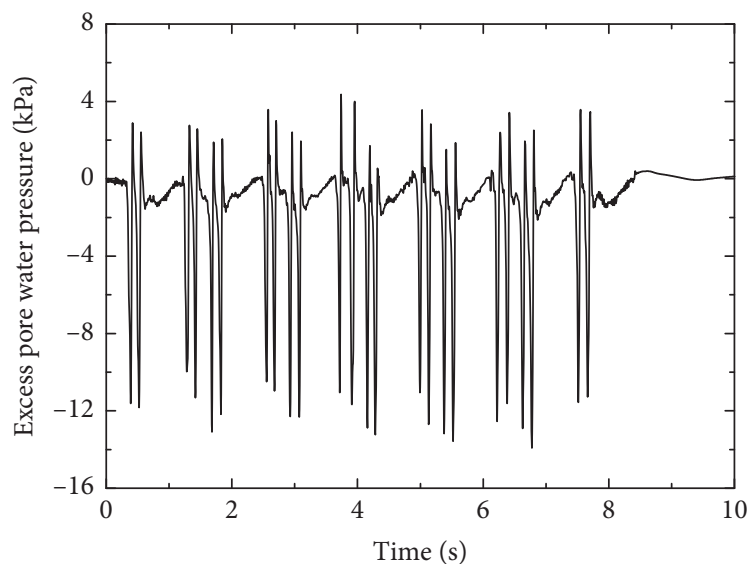

- Scenario I

(a)

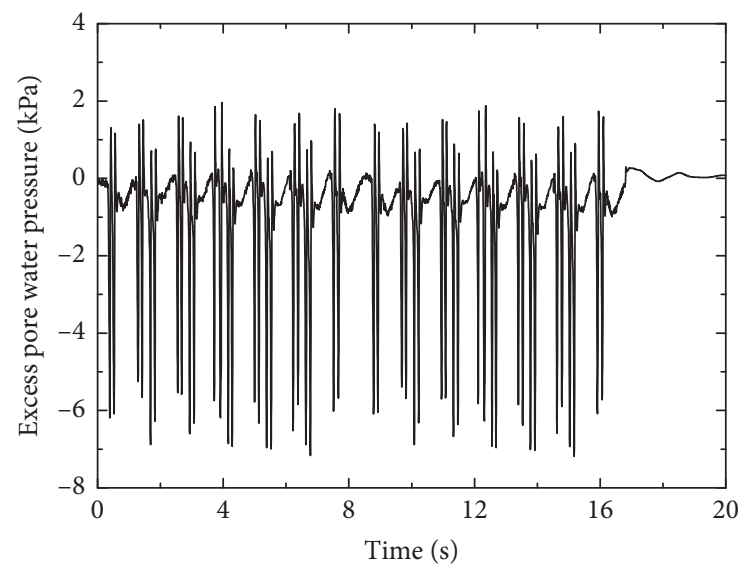

- Scenario III

(c)

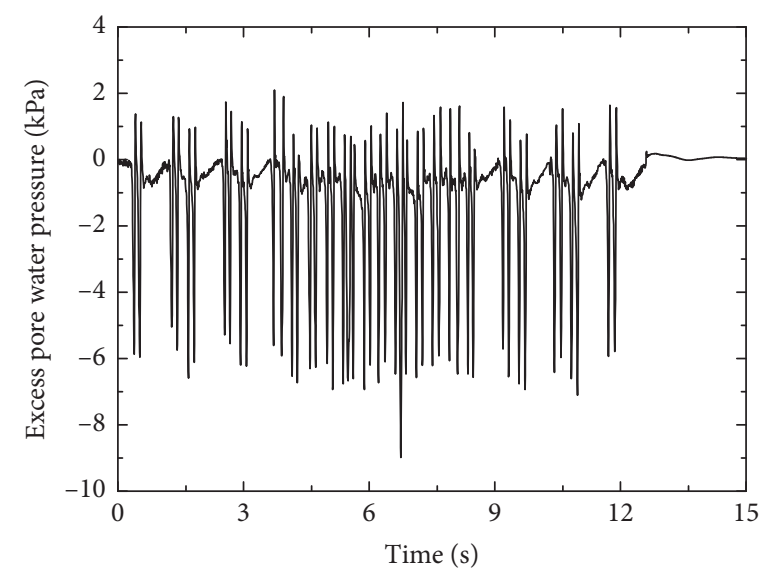

- Scenario II

(b)

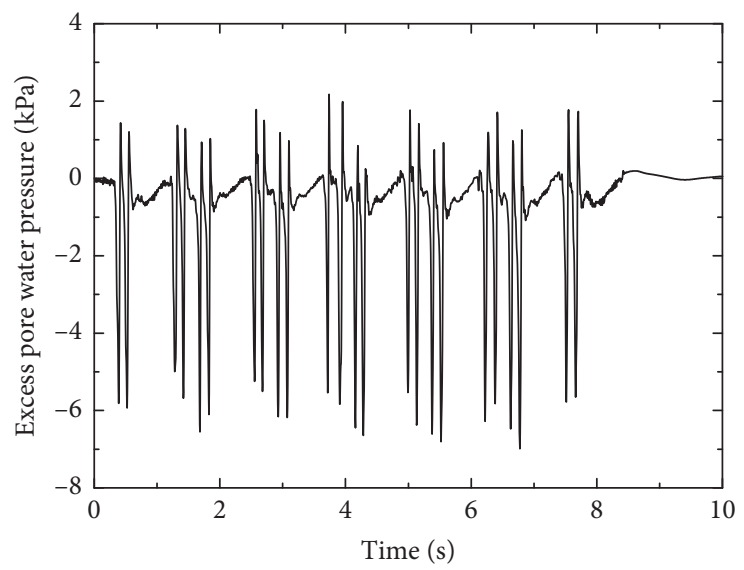

(d)

FIgURE 18: The excess pore pressure of $A_{1}$ in time domain. (a) Scenario I. (b) Scenario II. (c) Scenario III. (d) Scenario IV. 


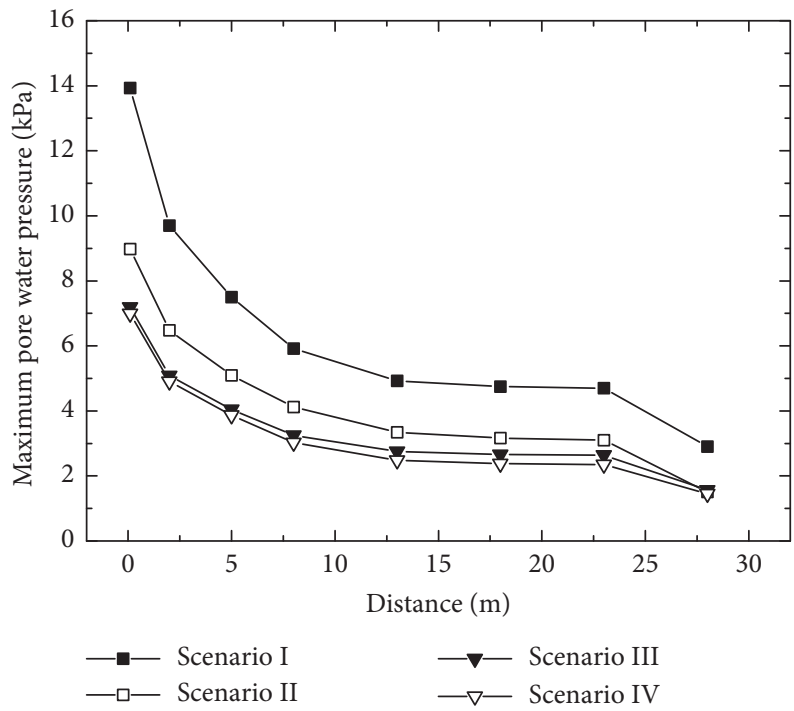

FIgURe 19: Trend of the maximum excess pore pressure.

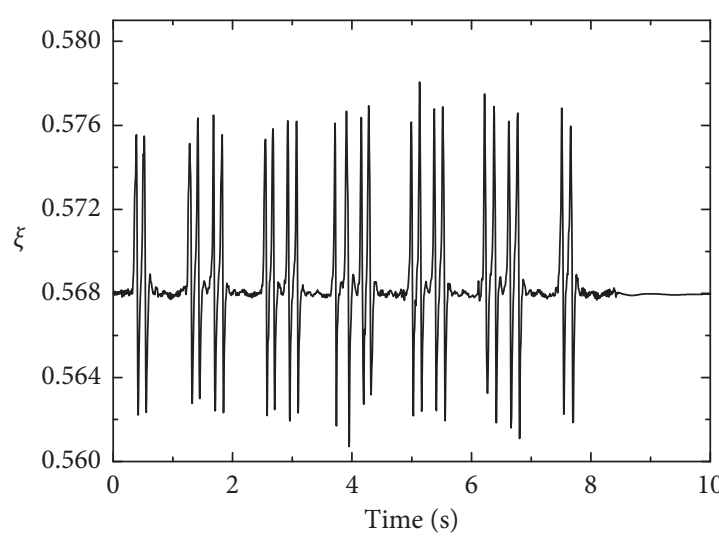

Scenario I

(a)

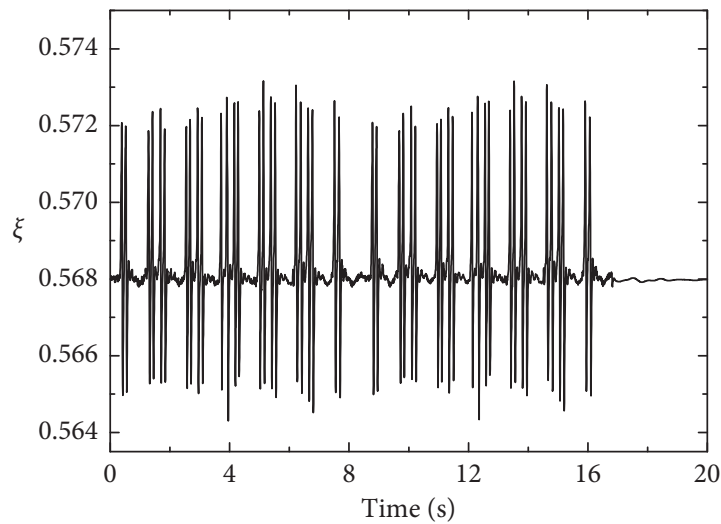

- Scenario III

(c)

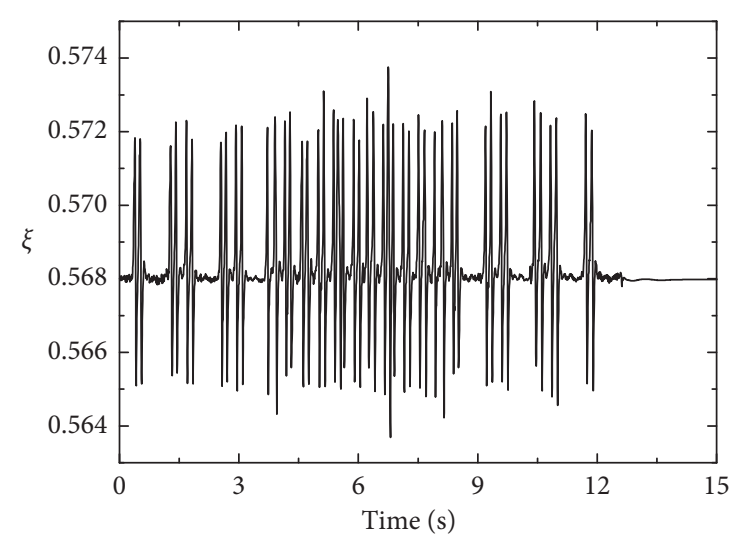

Scenario II

(b)

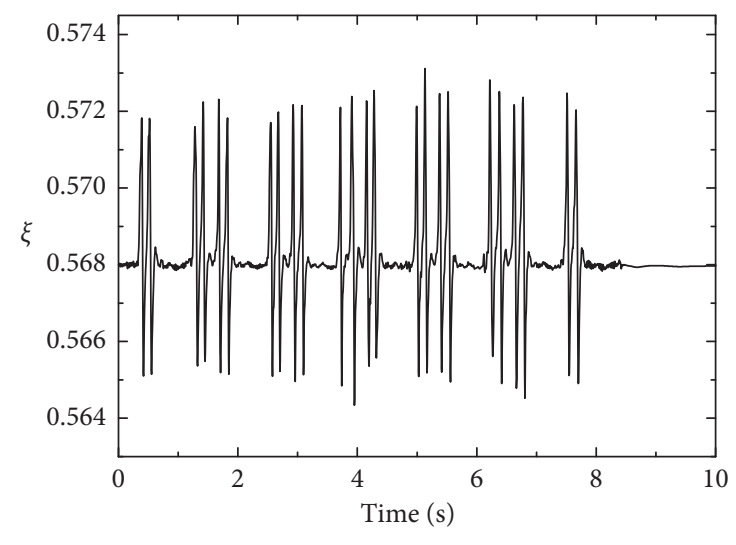

Scenario IV

(d)

Figure 20: $\xi$ value trends of $A_{1}$. (a) Scenario I. (b) Scenario II. (c) Scenario III. (d) Scenario IV.

scenarios. When the Metro trains pass the research section, the pore water cannot be drained out in time due to the transit nature of the dynamic load, so the excess pore water pressure is generated in the soil. When the Metro trains have passed by the section, the soil rebounds and the excess pore water pressure varies to the opposite. Peak excess pore 


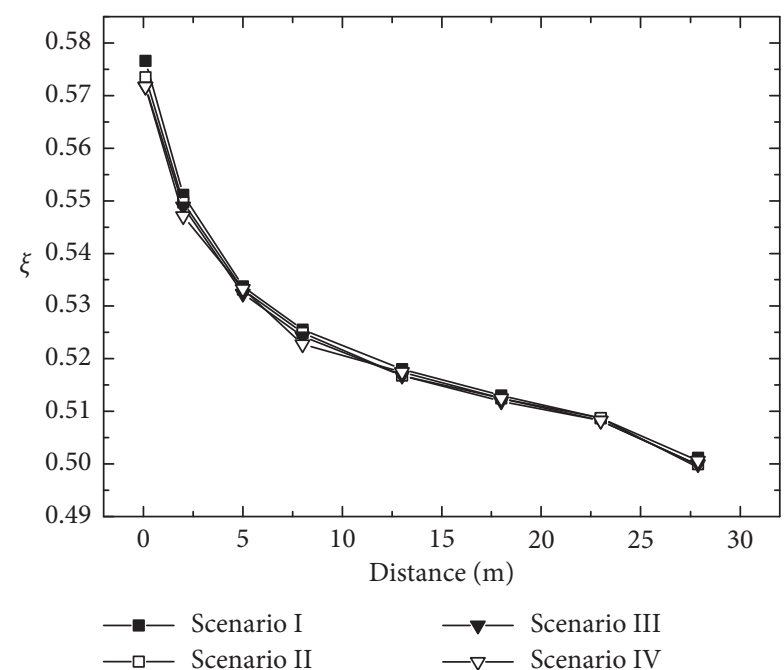

Figure 21: Trend of the maximum values of $\xi$.

pressure occurs in soil under the action of the train wheel sets. After the wheel sets leave the research section, the excess pore pressure decreases rapidly to near 0 . The greater the vibration amplitude yielded by Metro, the greater the excess pore water pressure occurs in soil. Because of the overlapping effect of loads, obvious multipeaks of the excess pore pressure occur in Scenario II during the interval of $4 \mathrm{~s}-8 \mathrm{~s}$. The maximum values of the excess pore pressure of Scenarios I, II, III, and IV are $13.93 \mathrm{kPa}, 8.98 \mathrm{kPa}, 6.99 \mathrm{kPa}$, and $6.98 \mathrm{kPa}$, respectively. The hydrostatic pressure is $272.2 \mathrm{kPa}$, and the excess pore pressure is about $1 / 30$ of that.

Figure 19 shows the maximum excess pore pressure curve of $A_{1}-A_{8}$. With the increase of the vertical depth, the maximum excess pore pressure decreases exponentially; beyond a certain depth range, the vibration vanishes. Due to the variation of soil damping, the decline rate of the maximum excess pore pressure varies. The abrupt decrease of the excess pore pressure, between $23 \mathrm{~m}$ and $28 \mathrm{~m}$ beneath the tunnel, mainly lies in the fact that this stratum is the moderately weathered mudstone, which is not capable of generating excess pore water pressure. At the same depth, due to the variations of the vibration intensity and duration, the trend of the maximum excess pore pressure, of $A_{1}-A_{8}$ in different scenarios, yields Scenario I $>$ Scenario II $>$ Scenario III $>$ Scenario IV. The excess pore pressure of Scenario III is close to that of the Scenario IV.

4.5. Liquefaction Potential. We used the direct criterion to evaluate the liquefaction potential of granular soils [20]. By calculating the ratio of the pore water pressure to total stress, the liquefaction potential of granular soil layer in tunnel basement induced by the Metro train motion is discriminated, which yields

$$
\xi=\frac{U}{\sigma},
$$

where $\xi$ is the ratio of pore water pressure to total stress; $U$ is the pore water pressure; and $\sigma$ is the total stress.
When $\xi$ is equal to 1 , meaning the pore water pressure is equal to the total stress and the effective stress is zero, the granular soil is in a liquefaction critical state. When $\xi$ is less than 1 , the effective stress of the granular soil is positive and we deem that no liquefaction occurs in the soil.

Figure 20 exhibits the variation trend of $\xi$ value of $A_{1}$ in different scenarios in the time domain. During the Metro operation, the excess pore pressure of the silty-fine sand under the tunnel produces repeated cycles of accumulation and dissipation. When the cumulative excess pore pressure is greater than the effective stress, the silty-fine sand is apt to liquefy and increase the underground settlement under the tunnel. As for the four scenarios, $\xi$ value varies periodically with the train load. The equilibrium value of $\xi$ in fluctuation is around 0.568, with little differences occurring for all the scenarios. Note that $A_{1}$ did not liquefy under all scenarios.

Figure 21 shows the trend of the maximum $\xi$ value varying with the depth for different scenarios. The maximum values of $\xi$ tend closely at the same depth under all scenarios. Moreover, with a depth increase beneath the tunnel, the maximum values of $\xi$ decreases from 0.58 to 0.5 , suggesting the liquefiability of the silty fine-sand soil decreases gradually with the increase of the depth. Thus, the silty fine-sand soil layer, beneath the single-track double-line tunnel, is not apt to liquefy.

\section{Conclusions}

We developed the wheel-rail force model of the A-type Metro train based on the multibody dynamics. Taking a research section of a single-hole double-track tunnel, of Nanjing Metro Line 10 as an example, a track-tunnel-soil model has been demonstrated; the dynamic responses of the acceleration, displacement, and strain of the soils around the tunnel and the liquefaction potential of the silty fine-sand soil layer under the tunnel were analyzed, respectively. The following conclusions can be drawn:

(1) The vertical acceleration of the tunnel substrata exhibits an exponential attenuation trend with an increase of the distance; the horizontal acceleration of the ground surface exhibits an enlarged area within $10-25 \mathrm{~m}$ from the tunnel centerline.

(2) The displacement of the soils under the tunnel increases cyclically in the period of the Metro train passing and rebounds slowly after the train passing. The displacement caused by the scenario of twoMetro-train meeting is generally 1.5 to 2 times that of single Metro train scenario.

(3) When the wheels of two Metro trains act simultaneously, the peak compression strain increases superimposedly; when the act is out of sync, the peak compression strain occurs concentrated and significant increase does not occur. With an increase of the vertical depth, the maximum dynamic strain decreases linearly.

(4) The larger the vibration amplitude is caused by the Metro train, the greater the excess pore water 
pressure occurs. The abrupt decrease of the excess pore pressure between $23 \mathrm{~m}$ and $28 \mathrm{~m}$ beneath the tunnel mainly lies in the fact that this stratum is the moderately weathered mudstone, which is not capable of generating excess pore water pressure. Beyond a certain depth range, the influence of the vibration vanishes.

(5) The $\xi$ of the silty fine-sand soil is less than 1 , suggesting the soils around of the single-hole doubletrack tunnel are not apt to liquefy under the cyclic loads exerted by the trains moving in both ways. Moreover, the liquefiability of the silty fine-sand soil gradually decreases with the increase of the depth.

(6) The large deformation induced by the soil liquefaction may result in longitudinal differential settlement of the tunnel, which influences the track flatness. The investigation results aid in regulating the running speed of the Metro trains and planning the maintenance measures for the track flatness of the tunnel.

\section{Data Availability}

The data used to support the findings of this study are available from the corresponding author upon request.

\section{Conflicts of Interest}

The authors declare that there are no conflicts of interest regarding the publication of this paper.

\section{Acknowledgments}

This study was financially supported by the National Science Foundation of China (grant nos. 40902076 and 41722209) and Science \& Technology Program of Suzhou (grant nos. SYG201611 and SYG201713).

\section{References}

[1] F. Qin, X. Zhang, and Q. Zhou, "Evaluating the impact of organizational patterns on the efficiency of urban rail transit systems in China," Journal of Transport Geography, vol. 40, pp. 89-99, 2014.

[2] H. Wang, X. Zhang, and B. Huang, "Study of a reasonable cross section type for a long-distance shield tunnel crossing under a river," Modern Tunnelling Technology, vol. 50, no. 6, pp. 139-146, 2013, in Chinese.

[3] Y. Shi, W. Zhang, K. Sun et al., "Rapid assessment of vibration environmental response of Metro trains by wireless sensor networks," Vibration and Impact, vol. 2, pp. 229-234, 2017, in Chinese.

[4] K. Sun, W. Zhang, H. Ding, R. E. Kim, and B. F. Spencer, "Autonomous evaluation of ambient vibration of underground spaces induced by adjacent subway trains using highsensitivity wireless smart sensors," Smart Structures and Systems, vol. 19, no. 1, pp. 1-10, 2017.

[5] K. Sun, W. Zhang, H. Ding, R. E. Kim, and B. F. Spencer, "Embedding human annoyance rate models in wireless smart sensors for assessing the influence of subway train-induced ambient vibration," Smart Materials and Structures, vol. 25, no. 10, Article ID 105023, 2016.

[6] K. Sun and W. Zhang, "Combined annoyance assessment of subway train-induced structural vibration and ambient noise," Shock and Vibration, vol. 2016, Article ID 3028037, 8 pages, 2016.

[7] G. Volberg, "Propagation of ground vibrations near railway tracks," Journal of Sound and Vibration, vol. 87, no. 2, pp. 371-376, 1983.

[8] M. E. Popescu, "Fundamentals of soil dynamics," Engineering Geology, vol. 20, no. 3, pp. 266-267, 1984.

[9] H. Xia, N. Zhang, and Y. M. Cao, "Experimental study of train-induced vibrations of environments and buildings," Journal of Sound and Vibration, vol. 280, no. 3-5, pp. 10171029, 2005.

[10] C.-d. Li, W. Zhang, H.-H. Zhu, P. Wang, J.-T. Ren, and B. F. Spencer, "Fast vibration characteristics analysis of an underwater shield tunnel using the accelerometer network enhanced by edge computing," Measurement, vol. 141, pp. 52-61, 2019.

[11] W. Zhai, K. Wang, and C. Cai, "Fundamentals of vehicle-track coupled dynamics," Vehicle System Dynamics, vol. 47, no. 11, pp. 1349-1376, 2009.

[12] L. A. Yang, W. Powrie, and J. A. Priest, "Dynamic stress analysis of a ballasted railway track bed during train passage," Journal of Geotechnical and Geoenvironmental Engineering, vol. 135, no. 5, pp. 680-689, 2009.

[13] H. R. Nejati, M. Ahmadi, and H. Hashemolhosseini, "Numerical analysis of ground surface vibration induced by underground train movement," Tunnelling and Underground Space Technology, vol. 29, pp. 1-9, 2012.

[14] F. C. Xue, "Dynamic responses of subway tunnel in clay stratum to moving loads," Arabian Journal for Science and Engineering, vol. 42, no. 3, pp. 1327-1340, 2017.

[15] Q. Gong, S. Zhou, and B. L. Wang, "Variation of pore pressure and liquefaction of soil in Metro," Chinese Journal of Geotechnical Engineering, vol. 26, no. 2, pp. 290-299, 2004, in Chinese.

[16] X. Jin, Z. Wen, K. Wang, and X. Xiao, "Effect of passenger car curving on rail corrugation at a curved track," Wear, vol. 260, no. 6, pp. 619-633, 2006.

[17] S. L. Grassie, Dynamic Modelling of Railway Track and Wheelsets, Cambridge University (England), Department of Engineering, Cambridge, UK, 1984.

[18] H. Huang and X. Zang, "Research and analysis on longitudinal deformation characteristics of shield tunnel," Journal of Underground Space and Engineering, vol. 22, no. 3, pp. 244251, 2002, in Chinese.

[19] Y. Zhou, "Simulation of vibration effect and sensitivity analysis of soil parameters in automated Metro station," Master's thesis, Nanjing University, Nanjing, China, 2017.

[20] J.-C. Chai and N. Miura, "Traffic-load-induced permanent deformation of road on soft subsoil," Journal of Geotechnical and Geoenvironmental Engineering, vol. 128, no. 11, pp. 907-916, 2002. 


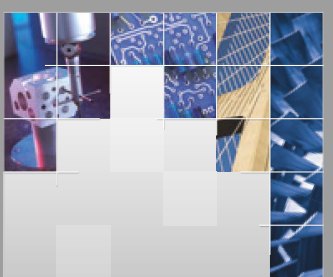

\section{Enfincering}
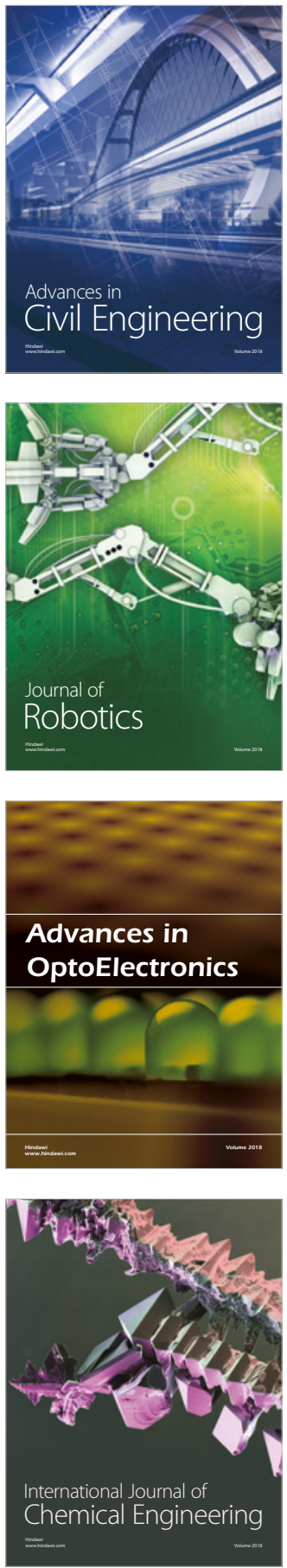

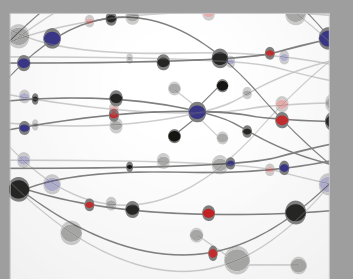

\section{Rotating \\ Machinery}

The Scientific World Journal

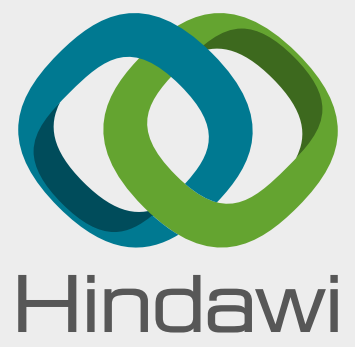

Submit your manuscripts at

www.hindawi.com
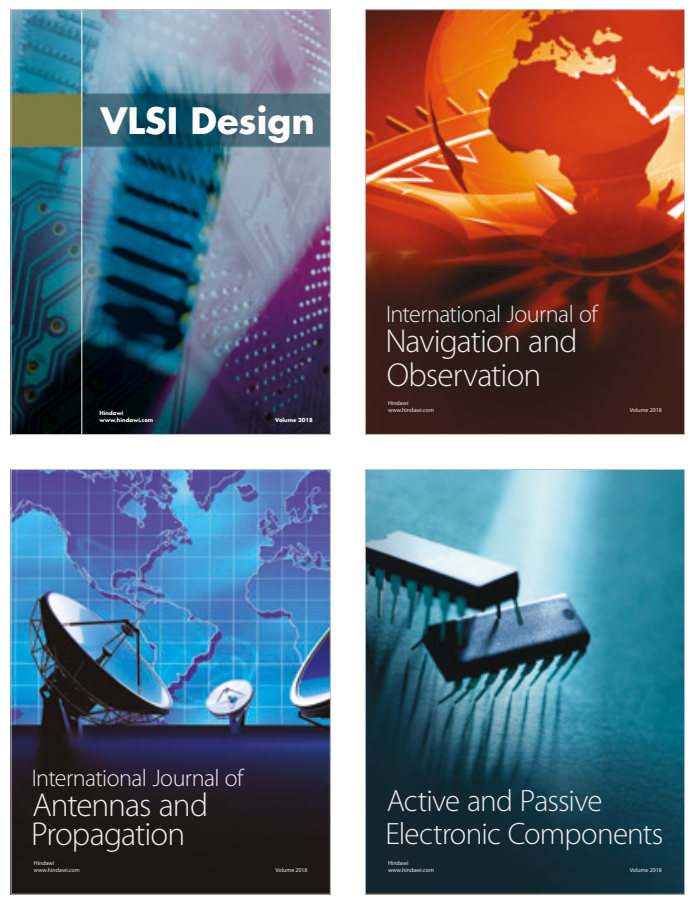
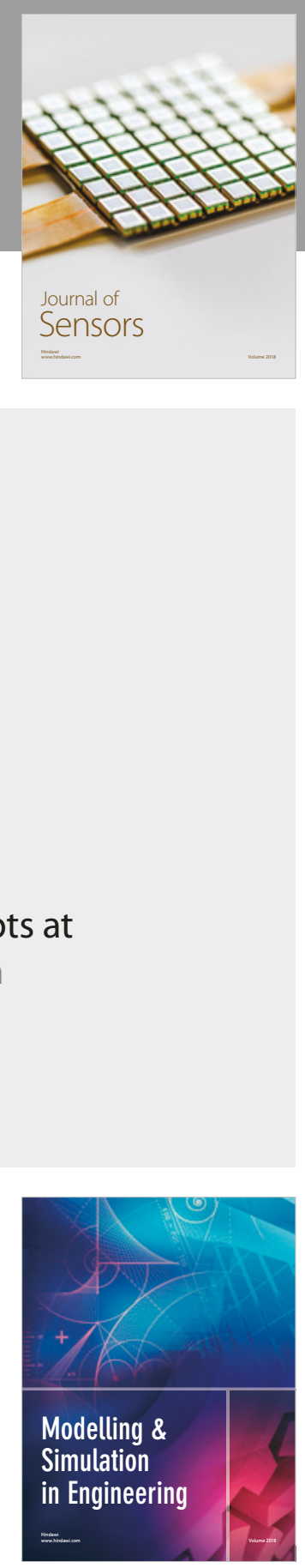

\section{Advances \\ Multimedia}
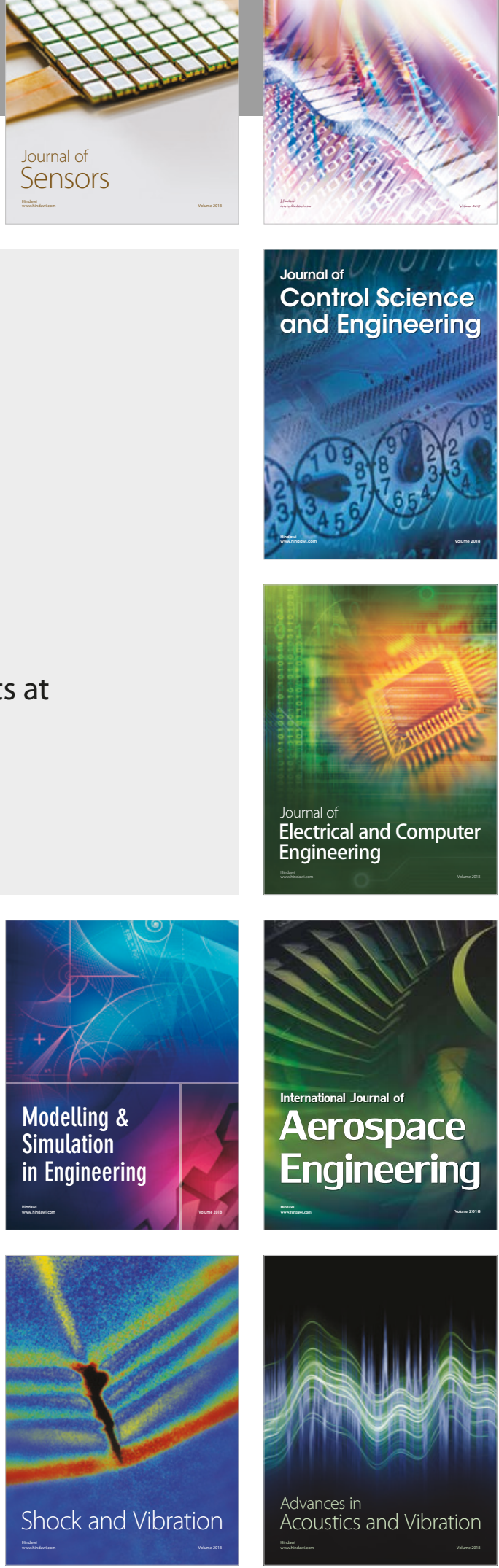